\title{
' LEGIBILITY
}

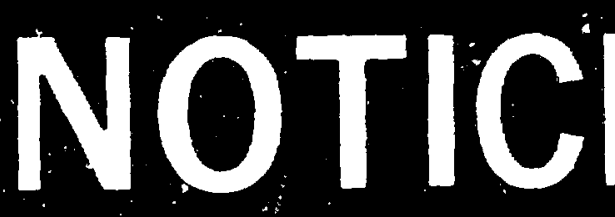

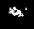

A major purpose of the Technical Information Center is to provide the broadest dissemination possible of information contained in DOE's Research and Development Reports to business, industry, the academic community, and federal, state and local governments. \section{Although a small portion of this} report is not reproducible, it is being made available to expedite the availability of information on the research discussed herein. 


\title{
SAFETY ANALYSIS REPORT
}

\author{
Location:
}

X17B2 Beamline/Synchrotron Medical Research Facility (SMERF)

National Synchrotron Lighe Source, BNL

Associated Project:

Trarssuenous Coronary Angiography with Synchrotron X-rays

- an addendum to the Phase II NSLS Safety Analysis Report

BNL \#52205, June 1989

Nicholas F. Gmur and William Thomlinson

February 1990

NATIONAL SYNCHROTRON LIGHT SOURCE

BROOKHAVEN NATIONAL LABORATORY

ASSOCIATED UNIVERSITIES. INC.

UPTON, NY 11973

UNDER CONTRACT NO. DE-AC02-76CHO0016 WITH THE UNITED STATES DEPARTMENT OF ENERGY

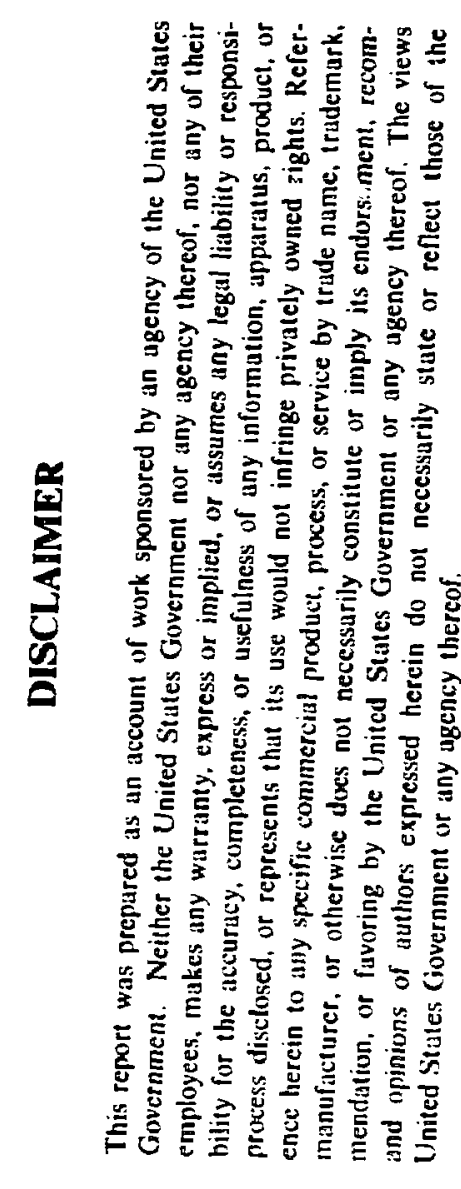




\section{Table of Contents}

1. Preliminary Statement ......................................................................................................................

2. Description of the Facility and Research Program ........................................................................ 2

2.1 SMERF Facility ................................................................................................................ 2

22 Research Program ......................................................................................................................... 2

2.3 Beamline Configuration .................................................................................................. 3

3. Building Systems ............................................................................................................................. 4

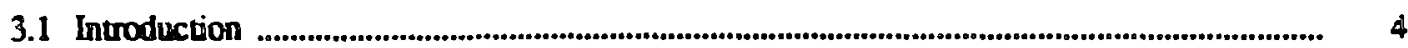

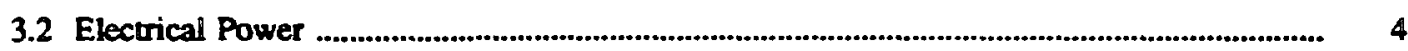

3.2.1 Circuit Box ........................................................................................................... 4

3.2 .2 Wiring ........................................................................................................................... 4

3.2.3 Grounds .......................................................................................................................... 4

3.2.4 Ground Fault intermuter (GFI) ........................................................................... 4

3.2 .5 Receptacles .............................................................................................................. 4

3.2.6 Emergency Lights ............................................................................................................... 4

3.2.7 Emergency Power Outlets .................................................................................................... 4

3.2.8 Emergency Generator ...................................................................................................................... 4

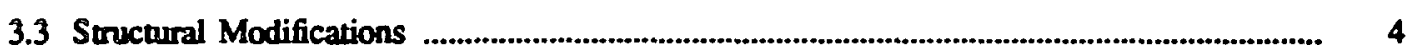

3.3.1 Stwel Column Modification ......................................................................................... 4

3.3.2 Life Safety .................................................................................................................. 5

3.3.3 Radiation Shielding ............................................................................................. 5

3.4 Building Access and Egress ................................................................................................. 5

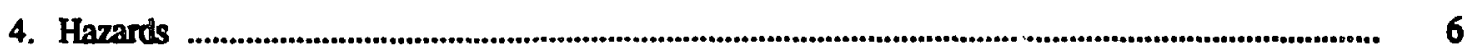

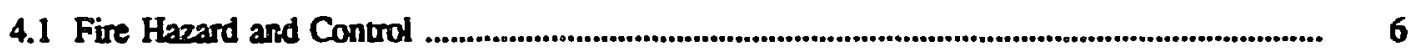

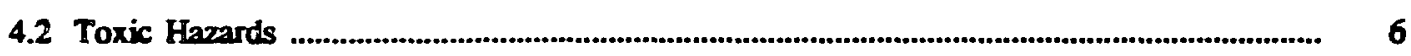

4.3 Laser Hazards ............................................................................................................................ 6

4.4 High Pressure Systems ............................................................................................................ 6

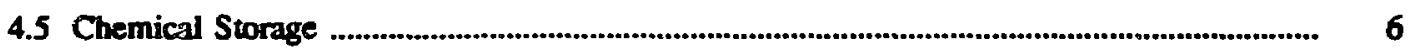

4.6 Ozone Production .......................................................................................................... 6

4.7 Cryogenic Hazards ......................................................................................................... 7

4.8 Magnetic Field Hazards ..................................................................................................... 7

4.9 Hazardous Wastes (Environmental Hazards) .................................................................. 7

4.9.1 . Photographic Wastes ............................................................................................................ 7

4.9.2 Medical Wastes ............................................................................................................. T

4.10 Radiation Hazards .................................................................................................................. 7

4.10.1 Comments ............................................................................................................. 7

4.10.2 Radiation Shielding ........................................................................................... 8

4.10.3 Radiation Monitoring ........................................................................................... 9 


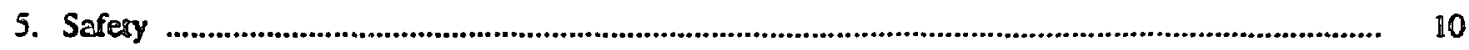

5.1 Operations (Safety Interlock Systems) ........................................................................ 10

5.1.1 Set-Up Mode .................................................................................................................. 11

5.12 Patient Mode ............................................................................................................. 11

5.2 Flsoroscopy Procedure ............................................................................................. 12

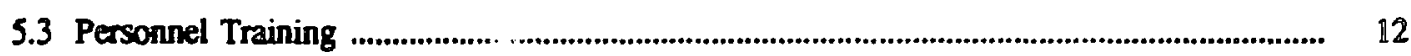

5.3 .1 Beamline Operation ....................................................................................................... 12

5.3 .2 Medical Staff ............................................................................................................... 18

5.3.3 Custodial Staff .................................................................................................................... 13

5.4 Equipment Calibration .................................................................................................... 13

5.5 Additional Oversight of Patient and Equipment Safety ....................................................... 13

5.5.1 Laboratory Safety Committee .................................................................................. 13

5.5.2 Human Studies Review Commitase ........................................................................... 13

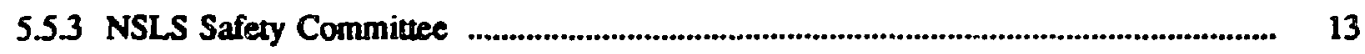

5.5.4 NSI.S Beamline Review Committee ............................................................................ 13

5.5.5 Clinical Research Center (CRC) Quality Assurance Committee ................................. 13

5.5.6 CRC Patient Care Commituee .................................................................................... 13

5.5.7 CRC Emergency Plans and Safety Commitree .............................................................. 13

5.5.8 Norh Shore University Hospital-Comell University Medical College
Human Studies Review Committee ................................................................................ 14

5.5.9 Stanford University Administrative Panel on Humas Subjects in Human Research ...................................................................................................................... 14

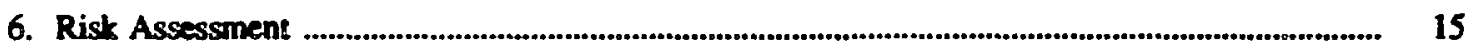

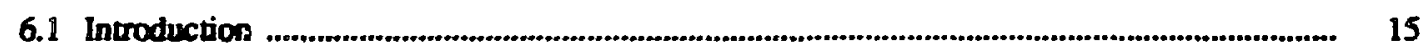

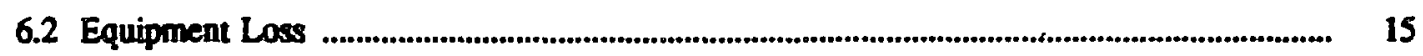

6.3 Radiation ..................................................................................................................... 15

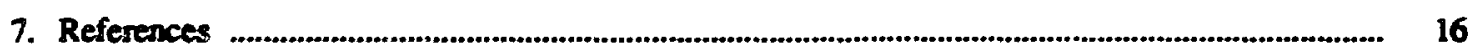

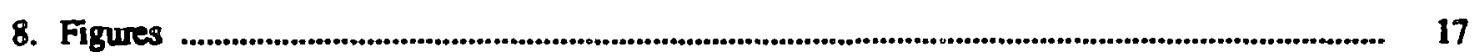

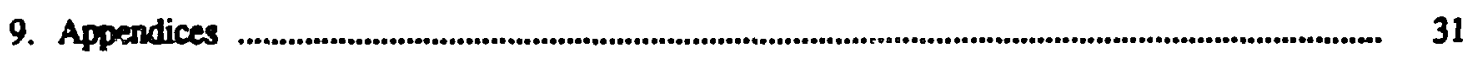




\section{Preliminary Statement}

This document should be treated as an addendum to the Phase II NSLS Safety Analysis Report (Ref. 1). The reasoning is that the X17B2 facilities and associated research program described herein are an extension of the "High Energy High Power Superconducting Wiggler Beamlines $[X 17]^{\text {" already }}$ described in Section 4.2 of the Phrse II document. As such, many NSLS and Xif related Policy, Building and Experimental Area iterns are already dealt with in detail and will only be referenced in this document where changes or differesces occur pertinent to the X17B2 facility and program. Based on DOE Order 5481.1B (Safety Analysis and Review System), the Synchrotron Medical Research Facility described in this SAR is classified in the Low Rist Hazard Class. 


\section{Description of the Facility and Research Program}

\subsection{SMERF Facility}

The Synchrocron Medical Research Facility, herearter called SMERF, was constructed as pan of the Phase II NSLS building expansion program. Figure 1 shows the relation of SMERF to the overall NSLS expe imental floor. The nine room, $180 \mathrm{~m}^{2}$ complex contains the downstrean portion of the $X 17$ Superconducting Wiggler beamline, designated as X17B2. Figure 2 shovis SMEPF in detail. The size of this medical research area is cictated by the fact that it must provide siace for a beamline and imaging detectrer equipment, beamline control and imaging computers, an imiging area, human patient and physician as well as physicist areas. Specifically, the facility consists of the following rooms:

a) Reception: patients, after having been admitted at the Clinical Research Center (BNL Medical Dept), will be brought here prior to the imaging procedure.

b) Toiles: for the convenience of the patients.

c) Fluoroscopy: devoted to catheterization of patients; location of $\mathrm{C}$-arm fluoroscopy unit, table and monita.

d) Dark Room: image processing area for photographic negatives, slides and prints.

e) Storage: equipment storage area.

f) Angiography: the room in which the coronary angiography imaging procedure will take place.

g) Phy: room from which the Responsible Physician will monitor and control the imaging sequences.

h) Data + Control: room for beamline control, imtaging and safety system computers and monitors.

i) Monochromator: continuation of beam pipe from X17B1 hutch enters this room and directs white $\mathrm{SR}$ beam to the X17B2 monochromator.

If addition to the above, SMERF is serviced across the hallway by an elevator large enough to contain a gurney plus attendants. The elevator communicates half a floor level up with an entrance and parting area for incoening and outgoing patients. This means that patients, under normal circumstances, will never see the experimental floor during their visits to the NSLS.

\subsection{Research Program}

While this SAR is iot intended to serve as a review of the merits of the medical research program, a brief cescription of that program is appropriate here in order to provide the reader with a frame of reference.

The Transvenous Coronary Angiography program had its inception in 1979 due to the combined efforts of researchers at Stanford Inivensity, Lawrence Berkeley Laboratory (LBL) and Stanford Synchrotron Radiation Laboratory (SSRL). The equipment and procedures have abready been proven on three sets of human patients (a total of six individuals). The research equizinent developed and built for the California program is now relocated and installed in SMERF.

Current medical practice for imaging human coronary arteries involyes the insertion of a cactheter into a leg or arm artery, guiding the catheter tip up the artery (high pressure, against the flow of blood) until it reaches the openings of the coronary arteries located in the proximal end of the arth. A radio-opaque dye (containing iodine) is injected into the coronary arteries and an $x$-ray image of the coronary ateries is teken using broad energy spectrum $x$-rays (10-100 keV).

Our technique is intended to be less invasive and thus reduce the risk to the patient by using the advantages of high fiux, tunable syuchrotron radiation. In this case, the catheter is inserted into a neck or arm vein (low pressure, with the flow of blcod). Visualization of the catheter during the catheterization 
procedure is accomplisted using a standard C-arm fluoroscopy unit. With the patien positioned in the imaging chair, the dye is injected by a power injector and evenusally enters the coronary areries. The $x$-ray imaging is done in dual energy digital subtraction mode. Two high intensity nassow energy band $x$-ray beams, ahove and below the iodine kedge (33.169 keV), are produced by a dual crysal monochromstor. The beams are directed so as to cross over at the patient's hearn and then continue ant in a dual 300 element linear deroctos: The patient is translated through the beam by the vertical motion of a chair. Fast-ecting safery shutters open only when the beams are over the heart region. Under typical operating conditions (see Section 5.1 for details) the patient can receive up to a 1.5 rad local skin surface dose per image scan. The low energy image is then digitally subtracted from the high energy image to remove bone and issue artifa-ts and the resulting image shows the coronary arteriex. Multiple images may be taken with each injection and the patient may undergo a series of images in more than one position to better project various arteries.

While the initial research period will ie devoted to angiography, plans are already being made for fubure programs in computed tomography (CT), cancer radictierapy and possibly human radiosurgery.

\subsection{Beamline Configuration}

The X17 beamline including wiggler, front-end components, transport hutches, X17C hutch and X17B1 hatch are described and diagrammed in Figs. 4.54.9 of the Phase II NSLS SAR (Ref. 1). The X17B2 portion of the beamline lies immediateiy downstream of the X17B1 hutch (Fig. 3) and accepts the central 5 mradian portion of the X17 wiggler SR beam. Fig. 4 shows the components as set up for the angioyraphy program. These consist of a dual crystal monochromator which monochromates and divides the white SR bean into two separate beams above and below the k-edge of the radio-opeque dye in use. The beams are defined by vertical slits, pass through dual fast-acting safety shulters, another photos shutter and finally a dual beam monitor. All these items are located in the Monochromator Room. The beams then pass into the Angiography Room where they proceed to the patien chair. There they cross and finally proceed to the dual 300 element linear detector. Shielding configurations will be detailed in Section 4.10.2. Safety systems and interlocks will be described in Section 5.1. 


\section{Building Systems}

\subsection{Introduction}

The general principles and explanations outlined in Section 3 of the Phase II NSLS SAR also apply to the X17B2/SMERF area. Detailed below are items which differ in some way from the generalized descriptions. The designation of SMERF as an Ambulatory Health Care Facility - see Appendix 1 - has a direct bearing on some of these differences. This Facility complies with the National Electrical Code, Article 517.

\subsection{Electrical Power}

\subsubsection{Circuit Box}

As a safety precaution, all SMERF outlet, lighting and electrical power wires have been routed to 2 single circuit panel board located in the Suppor Room. This limits access and prevents accidental power disruptions. Original sources of regular and emergency power will be yellow tagged to identify wires/circuits dealing with SMERF.

\section{2 .2 Wiring}

Type AC (Armor Cable) wiring has been substituted for any existing Type NM (Non-Metalic) wiring.

\subsubsection{Grounds}

All receptacles have insulated ground conductors.

\subsubsection{Ground Fault Inserrupter (GFI)}

GFI duplex outlets have been installed where appropriate.

\subsubsection{Receptacles}

Additional duplex outlets mounted in $\$ 3000$ raceways have been installed in all rooms where beamline equipment is located.

\subsection{Emergency Lights}

Two L-100 Exide Electronic 6V central emergency lighting units are mounted on Angiography and Physician Room walls. Remore lamps for five other rooms are wired to these units. Lamps from both systems are locased in the Angiography and Fluoroscopy Rooms in case one of the systems fails.

\subsection{Emergency Power Outlets}

Emergency power outlets have been installed in the Angiography and Fluoroscopy Rooms. These outbets are also supplied by regular power. The switch-over time to emergency power is approximately 10 seconds.

\subsection{Emergency Generasor}

The emergency generator is located in the basement of Bldg. 535. It is tested by PE cnce a month (no load on system) and is serviced once a year. See Appendix 2.

\subsection{Structural Modifications}

\subsubsection{Steel Column Modification}

A cutout in one flange of support column *36 located in the Angiography Room was required to accomodate the $x$-ray beams and equipment for the imaging procedure. The column was reinforced and all new structures plus welds passed inspection. See Appendix 3. 


\subsubsection{Life Safery}

Due to the existence of a 90' dead end distance created by the construction of the X17 enclosed beamline, a new emergency exit has been constructed through the old $x$-ray ring walkway wal] past the SMERF Fluonoscopy Room. An "Emergency Exit Only" crash-bar door is installed in this exit See Appendix 4. This is in full compliance with "Life Safety Code", NFPA101, Chapter 28 (Industrial Section) for the beamlines on the X-ray Ring floor, and Chapeer 12 (New Heaith Care; Ambulatory Health Care Facilities) for the various patient areas.

\subsubsection{Radiation Shielding}

In crder to ensure the safety of Non-Radiation Workers from SR and fluoroscope $x$-ray scatter in the SMERF area a 1/16" layer of lead was added to the walls of the Angiography, Fluoroscopy and Monochromator Rooms (covered by $1 / 2^{n}$ gypsum wallboard). The lead goes to a 7 height excepe behind the detector where it reaches a 12' height. Details are covered by PE Spec. 7471, available upon request.

\subsection{Building Access and Egress}

This topic has been dealt with in Section 3.3 of the Phase II NSLS SAR (Ref. 1) and in Sections 2.1 (SMERF Facility) and 3.3.2 (Life Safety) above. It is important to note, however, that an Adverse Reaction Plan will be developed by the Responsible Physician for the SMERF patients. Included in this plan will be a well established procedure for evacuating stabilized patients from the building via the nearby elevator or either of the $x$-ray floor roll-up doors. The plan will include cocrdination with emergency services (police, fire, ambulance) and will be drawn up in conjunction with the BNL Clinical Research Center (CRC) Emergency Plans and Safety Committee. 


\section{Hozards}

\subsection{Fire Hazard and Control}

Fire protection is being extended from the existing building system. Smoke detection is provided in the various suiles. Photo-electric Type detection is alternated with Ionization Type for best coverage. Twenty-five percent of the manufacturer's maximum recommended spacing is used to provide prompt detection. The system complies with NFPA 72E on the placement of fire protection devices.

Sprinkler protection is being extended from the existing wet pipe system. The occupancy is classified as an ordinary hazard Group II area as per NFPA 13, "Installation of Sprinkler Systems". Standard $165^{\circ} \mathrm{F}$ cemperature rated sprinkler heads have been installed. The system complies with NFPA 13's installation rules for sprinkler systems.

New research related equipment will be added. This will increase the loss potential for the area Major component values are $\$ 140,000$. (detector), $\$ 50,000$. (patient chair), $\$ 100,000$. (fluoroscopy equipment), $\$ 60,000$. (computers), $\$ 100,000$. (electronic equipment), $\$ 250,000$. (beamline equipment). Assuming total loss during a fire the loss potential is within limits of a sprinklered and smoke detector protected facility (DOE Order 5480.7). Replacement of components, should they be completely destroyed by fire, would take about 12 months. A version of the detector which could be used as is spare is being developed by colleagues at Lawrence Berkeley Laboratory, CA. It is possible that a spere fluoroscopy set-up could be borrowed from colleagues at North Shore University Hospital. It is also possible that spare computer components could be borrowed from other projects on the BNL site.

\subsection{Toxic Hazards}

None anticipated.

\subsection{Laser Hazards}

None anticipated.

\subsection{High Pressure Systems}

A 60 psi "house air" system services the beamline. Standard DOT compressed gas cylinders of helium and argon will be located outside the Monochromator Room. These cylinders will be appropriately secured in the Data/Control Room and the gasses piped into the Monochromator Room. The helium will provide the atmosphere inside the monochromator box and the argon will provide the dual beam monitor atmosphere.

\subsection{Chemical Suinge}

Emergency medical supplies will be kept in the Angiography Room in a crash cart locked with breakaway locks. Drugs, IV solutions, radio-opaque dyes, and other medical supplies will be stored in medical cabinets in the Angiography or Fluoroscopy Rooms. Supplies will be monitored by BNL Medical Department personnel (nurses and pharmacist).

Small quantities of standard chemicals (eg. solvents) will be kept in cabinets in the Data/Control Room or in the Storage Room.

Photo processing chemicals will be kept in the Dark Room.

\subsection{Ozone Production}

None anticipated. The white SR beam will be contained within either evacuated bean pipes or in a 
helium filled monochromator box. The monochromatic beams which pass through air for imaging purposes are not anticipated iv generate significant quantities of ozone.

\subsection{Cryogenic Hazards}

The linear detector located in the Angiography Room is the only piece of equipment utilizing liquid nitrogen. A dewar containing 25 liters is used to cool a cryogenic vacuum pumping system. $L N$ is resupplied manually every 2.3 days during use of the detector. Flash evaporation of the 25 liters of $L N$ would result in displacement of afproximately $8 \%$ of the room volume. This would result in a decrease of atmospheric oxygen from $20.9 \%$ to $19.3 \%$. While $19.3 \%$ is slightly below the OSHA low value of 19.5\% (Ref. 2), the slightly deficient oxygen condition would exist instantancously only upon the flash evaporation of the entire 25 liters of LN. Due to rapid dissipation, a substantial hazard would not exist even under this worst case scenario.

\subsection{Magnetic Field Hazards}

None anticipated.

\subsection{Hazardous Wastes (Environmental Hazards)}

\subsubsection{Photographic Wastes}

The Dark Room will house an automated photo processing unit for generating negatives, slides and prints of the angiographic $x$-ray images. A silver recovery system will be employed. All developer and fixer liquid wastes will be bouled, labelled and placed in the building's Waste Ccllection Area for proper disposal.

\subsubsection{Medical Wastes}

The angiographic imaging procedure involves the insertion of a catheter into a human patient, the use of IV solutions, the injection of imaging dyes and the removal of the catheter. Associated with this procedure will be the release of various human body fluids and the necessary use of various materials to clean up the fiuids. Thus, the procedure generates liquid, solid and "sharps" wastes which should be viewed as potentially infectious. The Medical Department has defined strict protocols for the handling and disposal of such wastes (see Appendix 5 and $Q$ ) by the medical personnel associated with the research project (such as physicians, nurses and matrons). NSLS personnel will not be involved in the procedures. Custodians assigned to Bldg. 725 will, however, be involved in the day-to-day cleanliness of the SMERF rooms. These custodiens will undergo a documented training course given by the Infection Contel staff of the BNL Medical Departmsnt. Custodial supervisors will inform the Infection Control staff when a new, untrained custodian begins work so that this new person may also be trained.

\subsection{Radiation Hazards}

- all radiation shielding and procedures conform with the ALARA philosophy (Ref. 3).

\subsubsection{Comments}

Shielding against radiation due to SR beam scacter is one of the most important hazards to be controlled in the SMERF area. A 5 mradian wide, high energy spectrum white SR bean ( $\left.E_{c} \leq 22.2 \mathrm{keV}\right)$ is directed to the X17B2 Monochromator Room where two monochromatic beams are crealed. These beams then proceed into the Angiography Room for human imaging purposes. Their power is eventually deposited in a lead beam stop downstream of the imaging detector. Radiation shielding is necessary to protect the medical and NSLS personnel both within the immediate vicinity of the Angiography and Monochromator Rooms and in the offices located above these rooms.

All radizion scatter, shielding and dose calculations have been done using the software program PHOTON developed by Dean Chapman (Ref. 4). The accuracy of PHOTON calculations was 
determined by Elke Bräuer and William Thomlinson (Ref. 5) by empirical measurements for a variety of configurations on bending magnet beamlines $(E=5 \mathrm{keV})$. PHOTON was always found to be slightly conservative in its calculations i.e. calculating slightly higher photon flux transmiso sion, scanter or dose than were actually measured.

\subsubsection{Ractiation Shielding}

Our shielding decisions have been govemed by the dose limits for Non-Radiation Worters as set forth in DOE Order 5480.11 i.e. $\$ 100$ mirem/yr. These limits resulted in the following shielding configuration:

\section{a) Angiography Room}

The existing walls consist of three layers of $5 / 8^{n}$ gypsum wallboard. The entire wall surface of this room is covered to a height of $7^{\circ}$ with $1 / 16^{\prime \prime}$ lead sheet. The two walls extending from the curner behind the detector are covered to a height of $12^{\circ}$ for a width of $8^{\prime}$. The doors each have a $1 / 8^{\prime \prime}$ steel thickness which is suffecient shielding thickness. Windows in the doors are covered with 1/8" lead equivalency glass. A physician's window in the wall between the Angiography and Physician Rooms consists of $1 / 8^{\prime \prime}$ lead equivalency clear plastic. The ceiling is at a height of $16^{\circ}$ and consists of 18 gauge $\left(0.048^{\prime \prime}\right)$ steel deck and at least $3^{n}$ cement. This serves as excellent shielding for personnel in the offices above. A lead beam stop is located downstream of the detector.

\section{b) Monochromator Room}

The existing walls consist of three layers of $5 / 8^{*}$ gypsum wallboard. The wall surfaces are covered with $1 / 16^{\prime \prime}$ lead sheet to a 7 "height except for the wall shared with the Angiography Room (already shielded) and the wall shared with the $x$-ray ring floor $\left(12^{n}-18^{n}\right.$ thick high-density concrete). The $1 / 4^{n}$ thick stainless steel monochromator box is contained within a "cave" consisting of $1 / 8^{n}$ steel $+1 / 4^{\prime \prime}$ lead $+1 / 8^{n}$ steel plates. This will adequately contain the white SR beam scatter. A lead bremsstrahlung shield is located downstream from the monochromator. The Monochromator Room steel door and ceiling provide adequate existing shielding.

\section{c) Fluoroscopy Room}

In addition to the above sources of white and monochromatic SR beam scatter, the Fluorosecpy Room will contain a mobile C-arm fluoroscopy unit (see Section 5.4 for maintenance information). The question of shielding the Fluoroscopy Room against the scattered $x$-ray radiation of this unit was presented to Dr. Salvatore Vacirca (see Appendix 7), Radiation Safety Officer for North Shore University Hospital, Manhasset, NY. For typical cardiac (arterial) catheterization procedures at North Shore, his calculations showed scattered radiation of $24 \mathrm{mR}$ wh. This doce value is based on fluoroscope output of 2 Roentgen/min., scattered radiation at $0.1 \%$ of primary at 1 meter, 4 patients/wk. at 3 minutes exch. His opinion was that the existing gypsum walls would be sufficient shielding for such cumulative scatter, but that if the patient load were increased, 1 $\mathrm{mm}$ of lead sheet to a height of $7^{\prime}$ should be installed in the walls. It should be noced, however. that our venous technique will take an average 6 second fluoroscopic nun time/patient (see Section 5.2), therefore our weekly cumulative scatter will be much less. Therefore, the $1.588 \mathrm{~mm}\left(1 / 16^{\prime \prime}\right)$ lead sheet we have installed will provide a more than adequete margin of radiation protection.

Figure 5 gives a diagranmatic presentation of the PHOTON calculations for shielding and resulting skin surface doses. Doses are given in mradhr. A white SR beam seatter source exists at the silicon crystal within the monochromator. Monochromatic SR beam scatter sources exist within both the Monochromator and Angiography Rooms. A worst case analysis of scatter was assumed for the Monochromator Room using ICRU4 cissue. The patient is the source of scatter in the Angiography Room and is also represented by ICRU4 unit density artificial tissue. Doses are alculated after the scatter has been absorbed by various shielding configurations: monochromator box + cave, Monochromator and Angiography Room 1/16" leaded walls (incl. 1.9" CaSO 4 ), steel doors, and an 18 gauge steel deck $+3^{\prime \prime}$ concrete ceilings located $16^{\circ}$ above floco level. 


\subsubsection{Radiation Monisoring}

A reasonable point of view is that the results of the PHOTON calculations should be used for guidance only and should not be treated as the final word. To that end, the commissioning of the X17B2 beamline and SMERF facility will be a real-time process utilizing the expertise of bermline as weil as S\&EP personnel. The NSLS Safety Officer and Operations Corrcinators will assist in rigorous radiation monitoring surveys of all areas surrounding the white and monochromatic SR beams, including the offices above the beamline. S\&EP will be asked to establish Innger term surveys (TLDs) for the area Any radiation leakage found will be dealt with immediately to the satisfaction of the safety personnel concemed.

The dose received by the patient will be the sum of the amount calculated from the dual bean monitor flux measurements and the amount estimated from the fluoroscopy procedure. A program for calibrating the above instruments for accurate dose measurements will be developed with the assistance of S\&EP and the Medical Department. The total dose allowable for any patient will be deternined by the Responsible Physician. 


\section{Sofety}

\subsection{Operations (Safery Interlock Systems)}

The safety system employed on the X17B2 beamline, Monochromator Room and Angiography Rocm will combine the properties of the standard NSLS safety interlock system and the Angiography Personnel Protection Interlock (APPI) system. The NSLS interlock system has been in use since 1982 and is detailed in Appendix VI of the NSLS Safety Analysis Report (Ref. 6). A complete, documented irterlock system test is performed by the NSLS Safety Officer every six months. The purpose of the NSLS intertock system is to provide a safe environment for researchers and exclucle thenr from areas of radiation. The APPI system was developed by Rober Hettel and staff at SSRL for their coronary angiography program. This system's capabilities have been tested and used in numerous phantom, animal and human patient runs at SSRL. The APPI system is now an integral part of the X17B2 beamline. Its purpose is to protect the patient being imaged from excessive radiation dose. The APPI system will undergo a review by the NSLS Safety Review Committee. Commituee membere will be assisted by Safety and Environmental Protection Division staff. No human research shall occur until the NSLS Safety Committee has given written and signed approval of the APPI system. The APPI system will not be enabled for human studies by an NSLS Safety Officer unil a) the NSLS Safety Committee approves the APPI system, b) this Safety Analysis Repart is approved by the BNL Assistant Director for Reacior. Safety and Security and c) the human sudies research program is approved by the Human Studies Review Commitue.

Operation of the X17B2 beamline must be done in sequence with the X17B1 beanline (see Figure 2). In order to allow the SR beam into the B2 Monochromator Room, the B1 plus transport hutches must be searched and interlocked.

Standard operations will have a transport pipe installed the length of the B1 hutch. This pipe is not part of the interlock system and is in place to eliminate air scatter in the B1 hutch. The white SR beam passes through the evacuated B1 transport pipe into the B2 monochromator box.

The Monochromator Room is treated in exactly the same fashion as a standard white beam hutch. The door into this room forms part of the interlock chain. Enting: is allowed only after closure of the front end safety shuter. A lead beam stop, which ensures that the white bean does not reach the patient, is located just downstream of the monochromator box. The monochromatic beam photon shutters are located in the Monochromator Room downstream from the monochromator. A photon shutwer similar in design 10 standard NSLS photon shutters, but consisting of a 0.75" thick lead shuter instead of a 5/8" thick copper shutter, is used for allowing entry (other than patients) into the Angiography Room. This shutter allows the Angiography Room to function as a normal monochromatic hutch. The angiography fast-acting safety shutter assembly is also located in the Monochromator Roon and is composed of redundant shutters, each shutter consisting of two steellead blades activated by rotary solenoids (fail closed), and is capable of closure in $<50 \mathrm{msec}$. The two shutters are operated simultaneously vis two separate logic chains. The fast-acting safety shuttess control the $x$-ray exposure for the inaging. Loss of electrical power to the fast-acting safety shutters results in closure of the rotary solenoids thereby blocking monochromatic beam entry into the Angiography Room.

The bounds of operation are that the ring current shall not exceed $250 \mathrm{~mA}$ and the wiggier critical energy (E) shall not exceed $22.2 \mathrm{keV}$ (Ref. 1, p. 37). The patient is exposed to monochromatic beams (and their harmonics) above and below $33.17 \mathrm{keV}$. In a standard thoracic image, exit skin surface dose due to $33 \mathrm{keV}$ photons is down by a factor of about a 1000, compared to entrance skin surface doee. due to attenuation (Ref. 7). If the chair stops, the patient will receive a $360 \mathrm{rads} / \mathrm{sec}$ skin doce rate over an area of $0.92 \mathrm{~cm}^{2}$ (actually $0.5 \mathrm{mmV} \times 184.5 \mathrm{mmH}$ dictated by beam focusing in the vertical and 5 mradH beam an $36.9 \mathrm{~m}$ frcm the source). Since the fast-acting safety shutters close in less than 50 msec based on recent tests at the NSLS, this would resull in a maximum additional local skin dose of less than 18 rads. 
The presence of the fast-acting safety shutters in the beamline is the most significant difference between X17B2 and all other NSLS beamlines. Since the shutters close in less than $50 \mathrm{msec}$, the Kirk-key lock on the normal entry door from the Physician Room into the Angiography Room will not be used during the patient imaging experiments. The door will be redundandy sensed to be in a closed position. This feature allows immediate entry in the event that a patient has a problem.

The Angiography Room is operated in two different modes. The selection of the proper interlock configuration is made by the NSLS Safety Oificer by unique key control.

\subsubsection{Set-Up Mode}

This is a non-patient mode in which the dual monochromatic $x$-ray beams are allowed into the Angiography Room. White beam is on the B2 monochromator. The X17 Transport Hutch, B1 Hutch and B2 Monochromator Room are interlocked. The Angiography Room undergoes a standard search with two timed search buttons and accompanying soundlight alams. The Kirt key and microswitch interlocks on the three doors are functional. The photon shutter opening occurs by pressing the physician scan switch. Closure occurs upon pressing the photon shumer closed button. The fast-acting safety shuters, allowing the beans into the Angiography Room, are controlled from the computer by beamline personnel and open only when all interlocks are satisfied. Tripping any docr interlock closes the fast-acting safety shutters and photon shumer.

\subsubsection{Patient Mode}

This mode is used only when imaging patients. White beam is on the $\mathrm{B} 2$ monochromator and the interlock chain is complete for the X17 Transport Hutch, B1 Hutch, B2 Monochromator Rocm and the three doors into the Angiography Room. The Physician or a person designated by the NSLS Safery Officer is in charge of a search of the Angiograpizy Roorn (no sound/ight alarms) and ensures that only the patient, if any, is in the room during operation of the imaging sequence. No timed search buttons are used. The door to the Reception and Flworoscopy Rooms are locked from the outside but are passable from the Angiography side. The door to the Physician Room is unlocked. This mode requires ation by two sperial keys. The first key, held only by NSLS safety personnel, is used to switch the APPI interlock circuits irom Set Up Mode to Patient Mode. The second key, held by either the Physician or a person designated by the NSLS Safety Officer. is used to enable the scan sequence. This ensures that it is only the Physician or designated person who can start a scan after searching the Angiograpiny Room. The Physician or designared person then presses and holds the sean switch button to initiate the scan sequence. The sequence automatically opens the photon shutter. The timing of the patient chair movements and fastacting safety shutter activation are controlled by the computer imaging program. A scan fault is detected if the scan switch button is released at any time during the scan sequence. Any pault detected by the APPI system causes the fast-acting safety shutter and photon shutter to close and latch out The NSLS Safely Cfficer nust re-enable the system before operations can resume. Additional conditions causing a fault include:

a) the patient chair translating up and doivn at a slower than preset speed while fast-acting safety shutters are open,

b) failure of either or both fast shutters to be closed when the patient is not within correct imaging positions or when scan sequence is over.

c) excoeding the total scan time preset by the physician,

d) entry into the Angiography Room doors by personnel,

e) conflict in hardware logic, and

f) incorrect voltage on shutter power supplies. 


\section{S.2 Fluoroscopy Procedure}

The introduction of a contrast agent for the imaging procedure requires the insertion of a catheter inio the venous system of the patient. Visualization of the catheter position is done using a fluoroscope. The catheter tip will be placed at the junction of the superior vena cava and the right atrium utilizing the brachial vein. Unlike cardiac (arterial) catheterization, venous catheterization is a very fast and uncomplicated procedure. Fluoroscopic run times for this procedure are 3-9 seconds. For the average patient, the fluoroscopic nu time will be 6 seconds during which the patient will receive a total skin surface dose of 180 millirads (based on 2 Roentgen/min. fluoroscope output) over a $9^{\prime \prime}$ diameter viewing area. During the catheterization procedure and the operation of the fluoroscope, "Do Not Enter" signs will be lit on the two doors leading into the Fluoroscopy Room.

The nurse and physician in the Flworoscopy Room will wear standard catheterization lab lead aprons. No radiation will penetrate these aprons. The estimated dose to exposed areas of the primary physician (individual clasest to the patient during fluoroscopic procedure) will be approximately 20 rirrem/procedure (pers. comm. Dr. Salvatore Vacirca, Medical Physicist, North Shore University Hospi:al). Attendant staff will receive less dose. Routine BNL film badges will be wom by fluoroscopy pessonnel.

\subsection{Personnel Training}

\subsubsection{Beamline Operasion}

All personnel coming to do research at the SMERF facility will be required to view the NSLS safety video tape which provides an introduction to NSLS experimental hutch entry systems, a description of radiation safety, fire alarms and evacuation procedures. Users will also attend the required BNL safety orientations or new NSLS orientation programs currently under development.

It is the responsibility of the Principal Investigator to train and document the training (see Appendix 8) of new SMERF personnel regarding beamline operation and safety systems as well as the facility safety responsibilities of the Responsible Physician. During Set-Up and Patient Modes it is the responsibility of the NSLS physicists to operate the beamline. The Principal investigator is responsible for overall safety and quality assurance. Prior to each imaging sequence, a checklist of beamlise and scan parameters is completed and signed by a physicist and the Responsible Physician (see Appendix 9).

Medical research sudies will be conducted according to the policies established by the Governing Body of the CRC. Individual protocols must be approved by the BNL. Human Studies Review Committee. The CRC Patient Care, Quality Assurance and Safety Committees ensure the proper implementation of the sudies. While on the BNL site, the patients are always under the supervision of a physician and/or a nurse. During Patient Mode it is the Respcrnsible Physician who ensures the safety of the patients. The Responsible Physician is also in charge of the Angiography Room and ensures that the patient is the only person in the Angiography Room during actual imaging.

\subsubsection{Medical Slaff}

Clinical Research Center (BNL) registered nurses, acting as clinical tiaison with visiting hospital personnel, will be responsible for clinical quality assurance activities and provide support to the angiography nurses during angiographic procedures.

Full-time cardiologists from accrediated hospitals will place the venous line for the $x$-ray contrast injection. These physicians are Board certified cardiologists who perform many elective cardiac catheterizations annually. These cardiologists will be assisted by cardiac research nurses who ane trained in cardiac angiography, CCU/ICU care, and cenisied in ACLS (Advanced Cardiac Life Suppor). 
Physician and nurse competency and training for all medical aspects of this project will be determined by the Executive Committee of the BNL Medical Department when granting clinical privileges at BNL.

\subsubsection{Custodial Staff}

As stated in Section 4.9.2, Building 725 custodians will undergo a training course given by Medical Department Infection Control staff. This course will address the specific needs of human research area cleanliness in SMERF.

\subsection{Equipment Calibration}

All beamline equipment inspection, maintenance and calibration will be the responsibility of the NSLS $\mathrm{X} 17$ beamline staff (physicists and technicians). Oversight will be done routinely by NSLS Safery Officer and safety coordinator inspections.

Inspection, maintenance and calibration of all medical equipment will be done on a scheduled basis by the Medical Equipment Maintenance Shop staff in the BNL Medical Department according to the requirements of the Joint Commission for Accreditation of Health Organizations (JCAHO) and using the computerized program already in place at the CRC (see Appendix 10). This includes an annual mechanical and electrical safety check, and verification that the fluoroscope meets the manufacturer's design specifications. Standard operation and maintenence of the fluoroscopy unit will follow the guidelines set forth in NCRP Report No. 102 (Ref. 8). Staff members of the Shop may exercise the right to train and assign specific X17B2 beamline or medical personnel to do various medical equipment inspection, maintenance and calibration jobs. Complete records of all work will be kept.

\subsection{Additional Oversight of Patient and Equipment Safety}

The coronary angiography/SMERF project, because of its human patient involvement in the research prowacol, is overseen by many commituees. A brief sview of the committees is a useful exersise to demonstrate the breadth of issues concemed.

\subsubsection{Laboratory Safety Committee}

A BNL committee which reviews Safety Analysis Repors and recommends for approval to ti.e BNL Assistant Director for Reactor, Safety and Security.

\subsubsection{Human Studies Review Committee}

A BNL committee which reviews the medical, ethical, scientific and legal aspects of research protocols and patient safeguards.

\subsubsection{NSLS Safety Committee}

Reviews beamline and research safety issues peculiar to the NSLS facility.

\subsubsection{NSLS Beamline Review Commituee}

Reviews construction, vacuum and shielding configurations on new beamlines.

\subsubsection{Clinical Research Center (CRC) Qualiry Assurance Commitsee}

Reviews quality and appropriateriess of patient care as well as improvement of patient care.

\subsubsection{CRC Patient Care Committee}

Monitors inspection control, medical record review, physician competence and determination of breach of research protocol.

\subsubsection{CRC Emergency Plans and Safery Commituee}

Reviews and audits all aspects of patient and staff related safety at the facility. 
5.5.8 North Shore University Hospizal-Cornell University Medical College Hunan Studies Review Commitsee

Because patients and physicians from North Shore University Hospital are involved in this research, the research protocols were reviewed and approved by this Committee on March 12, 1989. This Commituee requires a Progress Report every 12 months (N.I.H. Assurance of Compliance No. M-1302).

5.5.9 Sianford University Administrative Panel on Human Subjects in Human Research

Because personnel from the Stanford Synchrotron angiography group are involved in this research, the research protocols were reviewed and approved by this committee on June 6, 1989. The research projects must be reviewed and re-approved annually by this panel (N.L.H. Assurance No. M-1272). 


\section{Risk Assessment}

\subsection{Introduction}

The NSLS Phase II SA.R (Ref. 1) has already covered the major safety features and assessed the various risks for the Phase II NSLS facility as a whole. Only those risks directly related to SMERF and coronary angiography will be dealt with below. Risk categories are taken from the DOE Risk Assessment Course (Fig. 6).

\subsection{Equipment Loss}

While malfunctioning equipment migh: result in a radiation risk (described below), actual damage to equipment (desector, patient chair. fast-acting safety shutters, monochromator crystals, etc.) would result in the expense of repairs and delay of the research program. The risks assessed are as high as Critical (II) for the detector but Marginal (III) for the other equipment, with a Remote (D) as a probability for any loss. Equipment Loss During a Fire has been analyzed in paragraph 3.5. It is within the limits of DOE Order 5480.7.

\subsection{Radiation}

As described in Section 5.1.2 above, there is a risk to the patient of over-exposure to the dual $x$-ray imaging beams due to either slower than preset chair speed, chair stoppage during the fast-acting safety shutuer imaging period, or a failure of the fast-acting safety shutters to close when commanded by the computir imaging programs. In those cases, fault conditions would arise immediately calling for the closure of the B2 fast-acting safety shuters and photon shutter. The risk to the patient is assessed as Marginal (III) resulting in an $x$-ray dose of 18 rats $/ 50 \mathrm{msec}$ (see Section 5.1 above) and is considered Remote (D). While exposure to the white SR bean would certainly be Critical (II) and result in a skin surface dose rate of about $6.9 \mathrm{E}+06 \mathrm{rads} / \mathrm{sec}$ over an area of $5.0 \mathrm{mmV} \times 184.5 \mathrm{mmH}$ (Ref. 4), the probability is Extremely Improbable (E) because of the positioning of the $0.25^{n}$ thick stainless steel monochromator box, the $8^{n}$ thick bremsstrahlung shield, the $0.25^{\prime \prime}$ steel $0.25^{\prime \prime}$ lead monochromator cave and

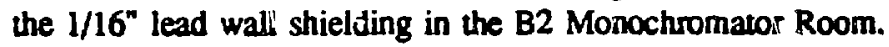




\section{References}

1. Stefan, P. June 1989. Phase II Safety Analysis Report National Synchrotron Light Source. National Synchrotron Light Source, Brookhaven National Laboratory, Upton, NY. BNL \$52205. $131 \mathrm{pp}$.

2. American National Standard Institute, Inc. 1980. Practices for Respiratory Protection. Volume Z88.2-1980. p. 14.

3. U.S. Nuclear Regulatory Commission. October 1982 (Rev. 1). Regulatory Guide 8.18: Information Relevant to Ensuring that Occupational Radiation Exposures at Medical Institutions Will Be as Low as Reasonably Achievable. 14 pp.

4. Chapman, D. January 1988. PHOTON: A User's Manual. National Synchrotron Light Source, Brookhaven National Laboratory, Upton, NY. BNL Informal Report \#40822. 61 pp.

5. Bräuer, E. and W. Thomlinson. 1988. Experimental Verification of PHOTON: A Program for Use in X-Ray Shielding Calculations. Nucl. Instr. and Meth. A266: 195-198.

6. Batchelor, K. (ed.). July 1982. National Synchrotron Light Source Safety Aralysis Repor National Synchrocron Light Sowce, Brookhaven National Laboratory, Upton, NY. BNL $\$ 51584$. $121 \mathrm{pp}$.

7. Nordstrom, E., N. Gmï, D. Chapman, M. Collins and W. Thomlinson. November 1989. Dose Rate to Human Organs from Monochromatic Synchrotron Beams. National Synchrotron Light Source, Brookhaven National Laboratory, Upton, NY. BNL Informal Report 43433. 11 pp.

8. National Council on Radiation Protection and Measurements. June 30, 1989. NCRP Repart No. 102: Medical X-Ray, Electron Beam and Gamma-Ray Protection for Energies Up to $50 \mathrm{MeV}$ (Equipment Design, Performance and Use). 139 pp. 
8. FIGURES 


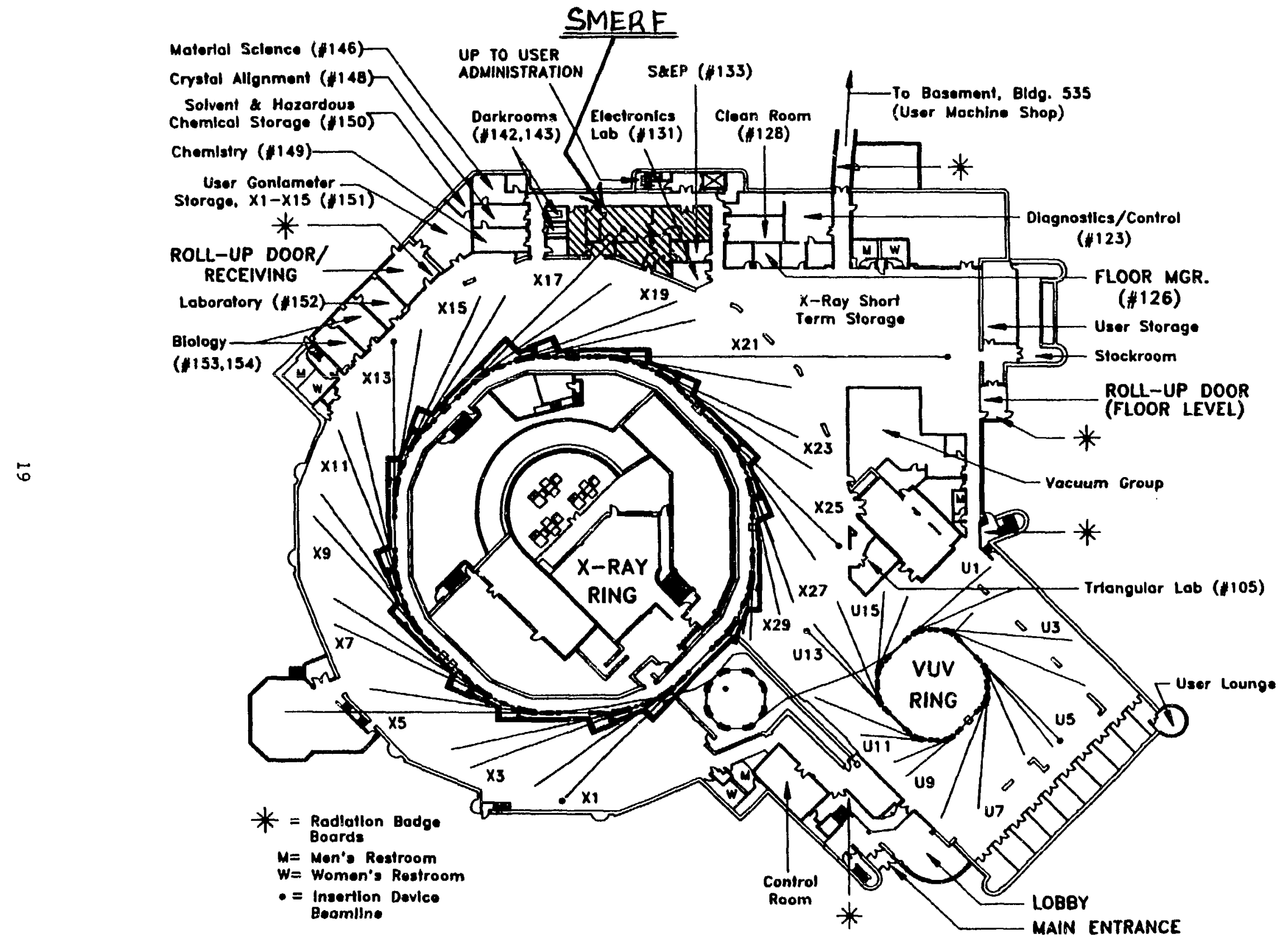

Higure 1: NSLS experimental floor with Synchrotron Medical Research Facility (SMERF) highlighted. 


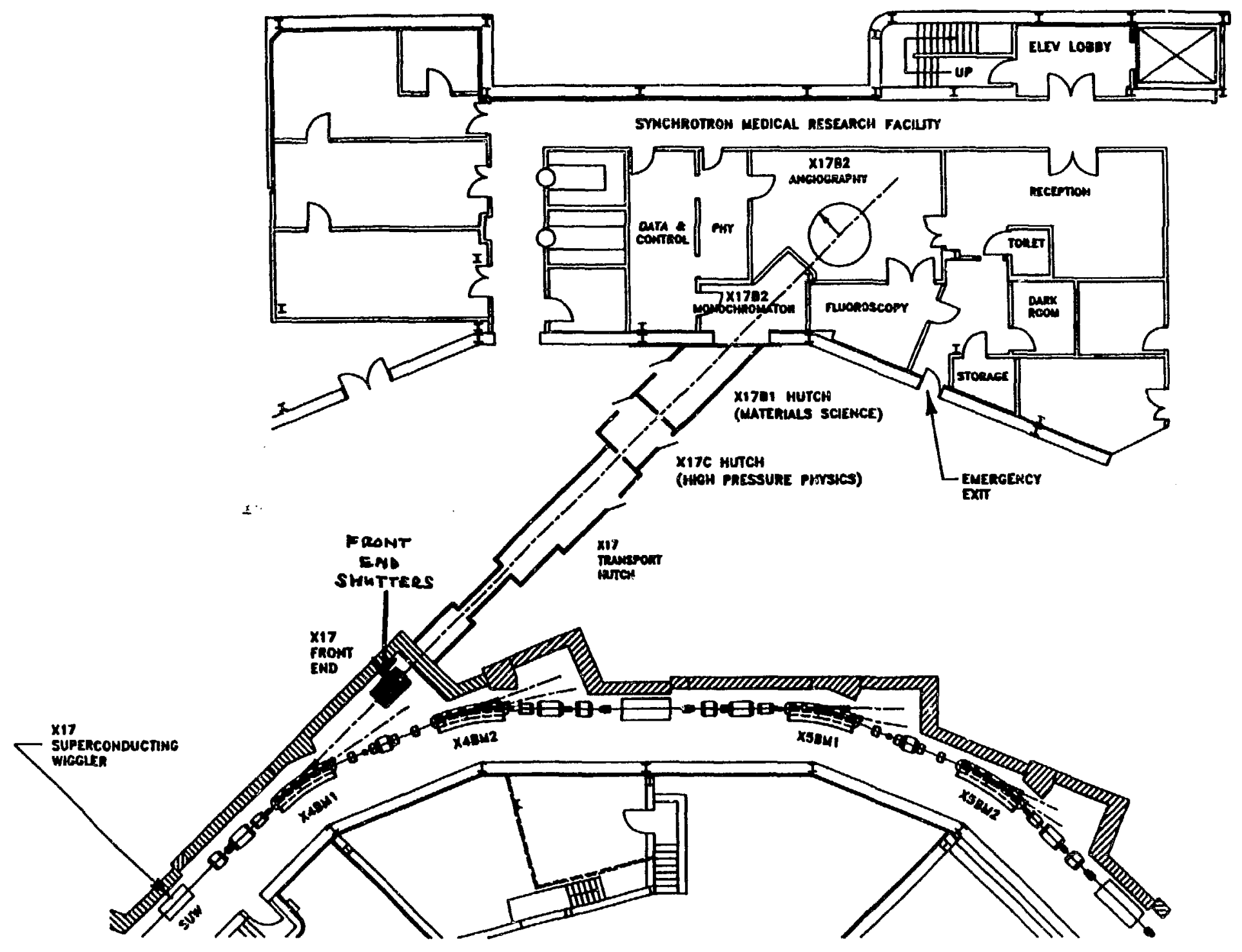

Figure 2: Synchrotron Medical Research Facility (SMERF) in detail. 


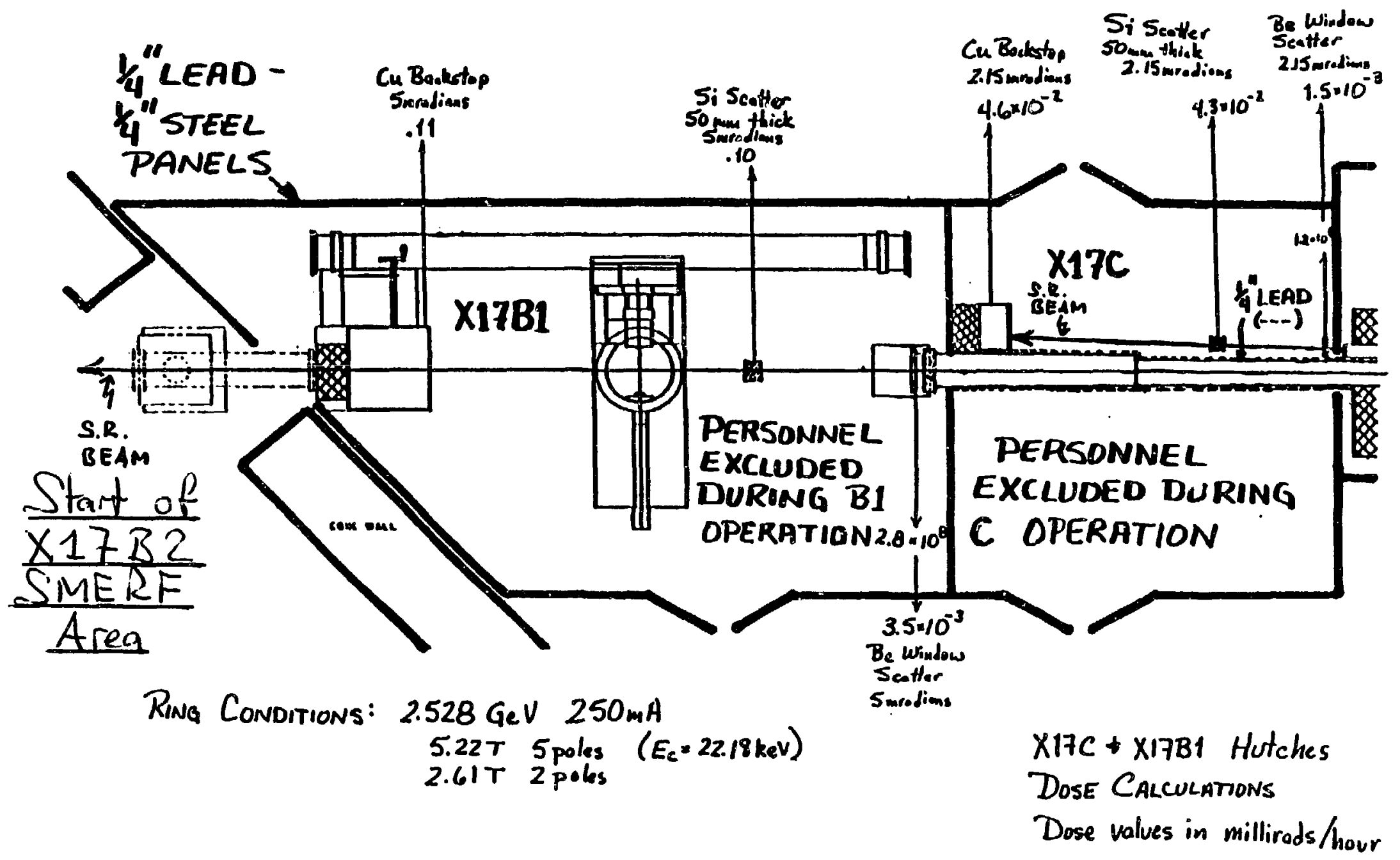

Figure 3: X17B1 hutch leading to downstream X17B2 (SMERF) area. 


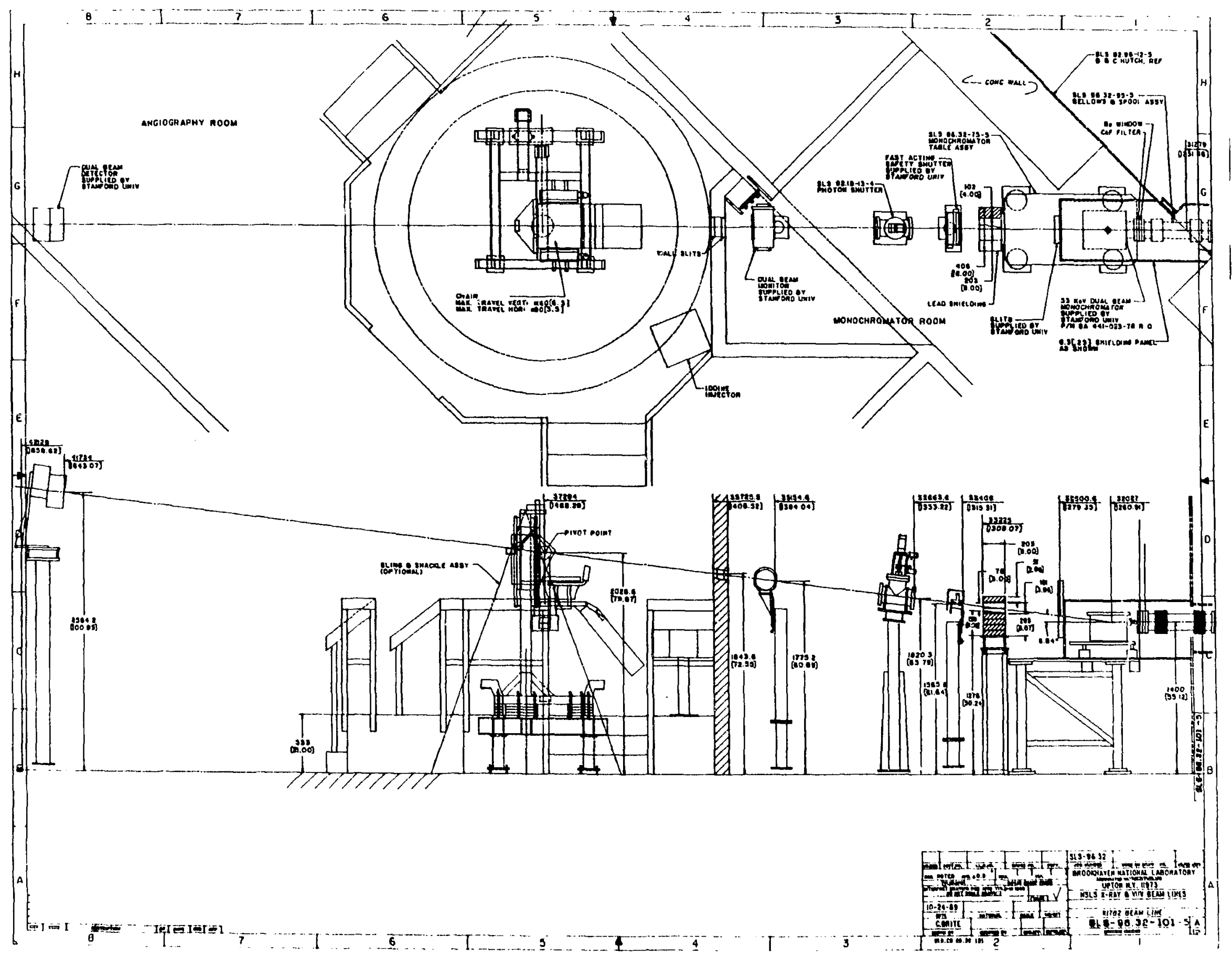

Figure 4: Plan and elevation views of X17B2 (SMERF) beamline components in Monochromator and Angiography Rooms. 


\section{SYNCHROTRON MEDICAL RESEARCH FACILITY}

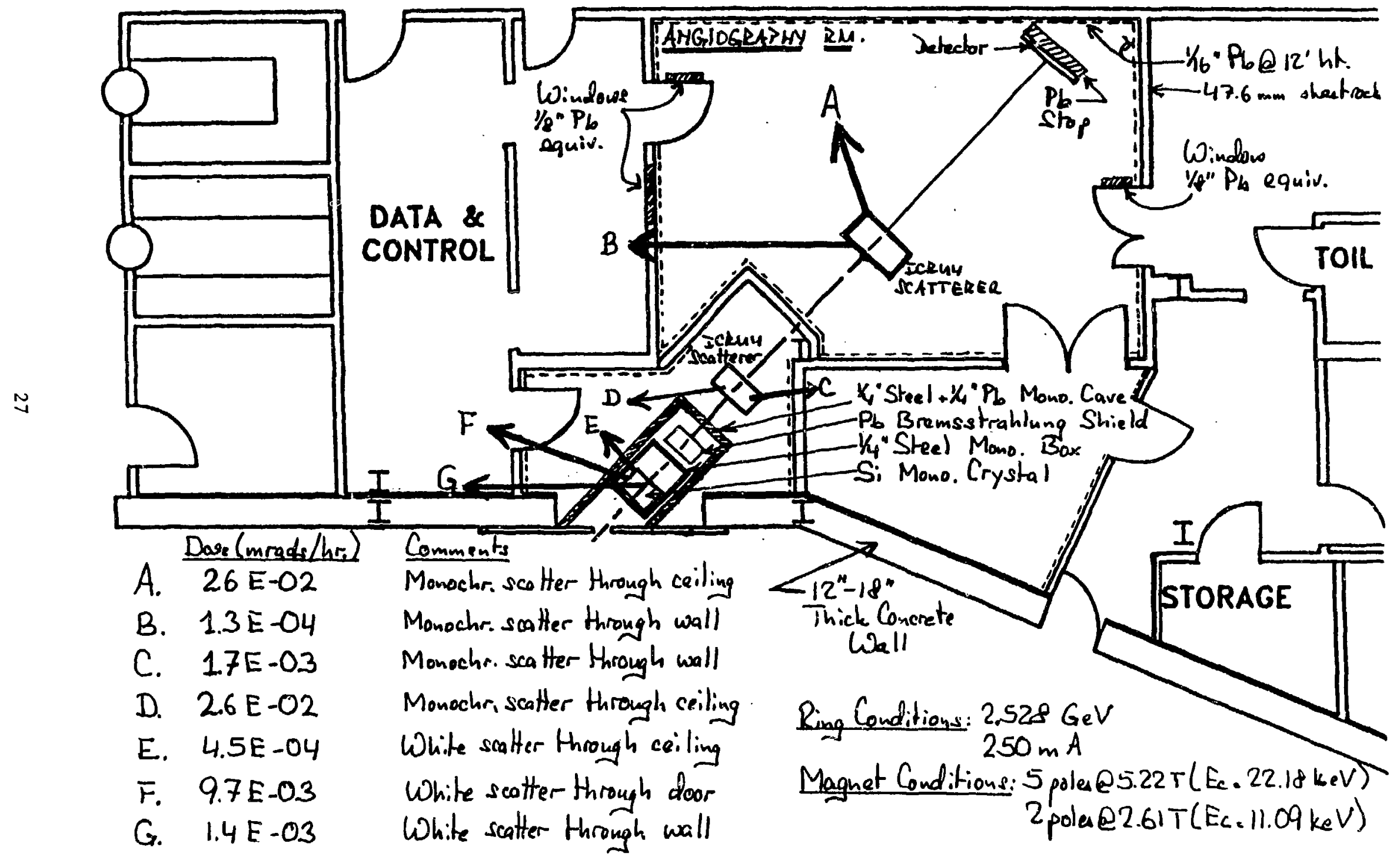

Figure 5: Shielding for X17B2 (SMERF) Angiography and Monochromator Rooms and beamline with resulting PHOTON calculated doce values. 
- AISK ASSESMENT -

\begin{tabular}{|c|c|c|c|c|c|c|c|c|c|c|c|c|}
\hline \multirow{2}{*}{\multicolumn{2}{|c|}{ coloener }} & \multirow[b]{2}{*}{$\begin{array}{l}\text { Doseceipitus } \\
\text { Wrete }\end{array}$} & \multicolumn{4}{|c|}{ POTENIIAL CONSEOUENCES } & \multicolumn{6}{|c|}{ PROBAGILITY" } \\
\hline & & & Poroconal & $\begin{array}{l}\text { Fanpmant } \\
\text { |ose (10) }\end{array}$ & $\begin{array}{l}\text { Tool Unlt } \\
\text { Downithe }\end{array}$ & $\begin{array}{c}\text { Dasio } \\
\text { Compondas }\end{array}$ & Finguent & Plononelly & $\begin{array}{c}\text { C } \\
\text { Oecentonel }\end{array}$ & $\underset{\text { nomole }}{D}$ & 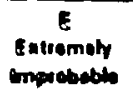 & Inpocetole \\
\hline \multirow{4}{*}{ 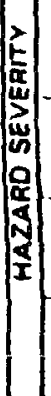 } & 1 & Corosureptic & Doush & $>100.000$ & $>4$ Months & 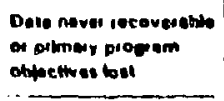 & 10 & 10 & YOYOY & $E$ & & \\
\hline & - & Comisent & 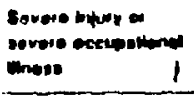 & $\begin{array}{c}100.000 \\
10 \\
100.000\end{array}$ & 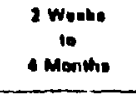 & 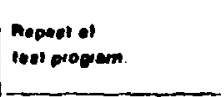 & YOP. & $\because 11$ & $\equiv(0) \equiv$ & & & \\
\hline & - & Margen & 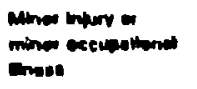 & $\begin{array}{c}1000 \\
1000 \\
100.900\end{array}$ & $\begin{array}{l}100 y \\
10 \\
100010\end{array}$ & $\begin{array}{l}\text { Anposi of } \\
\text { wot ponted. }\end{array}$ & $E$ & $E$ & & (3)* & & \\
\hline & n & 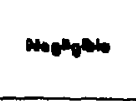 & 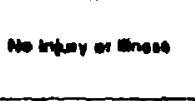 & $<1000$ & S lour & 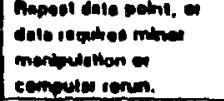 & & & & & & \\
\hline
\end{tabular}

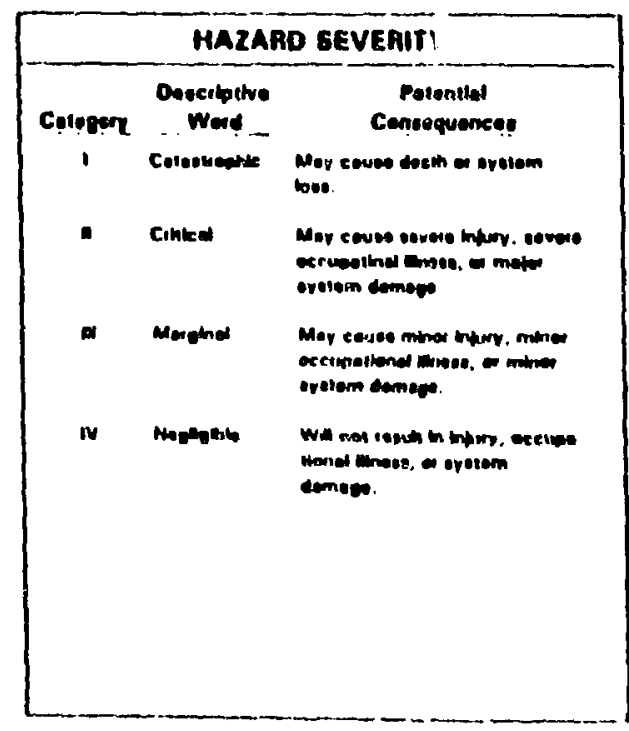

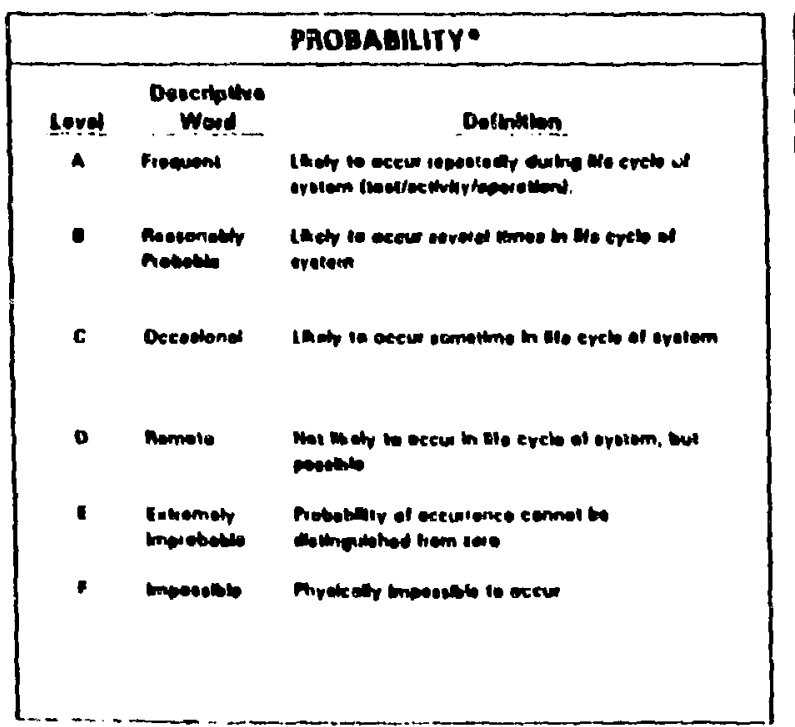

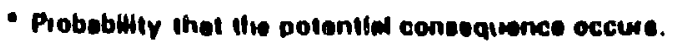

\begin{tabular}{|c|c|}
\hline \multicolumn{2}{|r|}{ AISK PAIORITY } \\
\hline (O) & 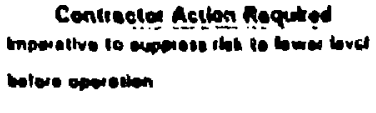 \\
\hline$\equiv 0$ & 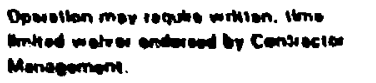 \\
\hline (3) & 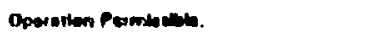 \\
\hline 2,0 & 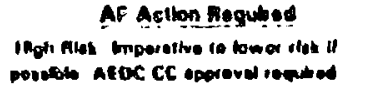 \\
\hline$\equiv(2) \equiv$ & 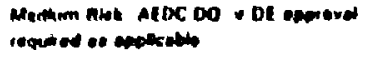 \\
\hline (D) & 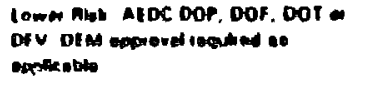 \\
\hline
\end{tabular}

Pigure 6: Risk categories from the DOE Ri:t Assessment Course. 


\section{APPENDICES}




\section{BROOKHAVEN NATIONAL LABORATORY}

ME MORA N D U M

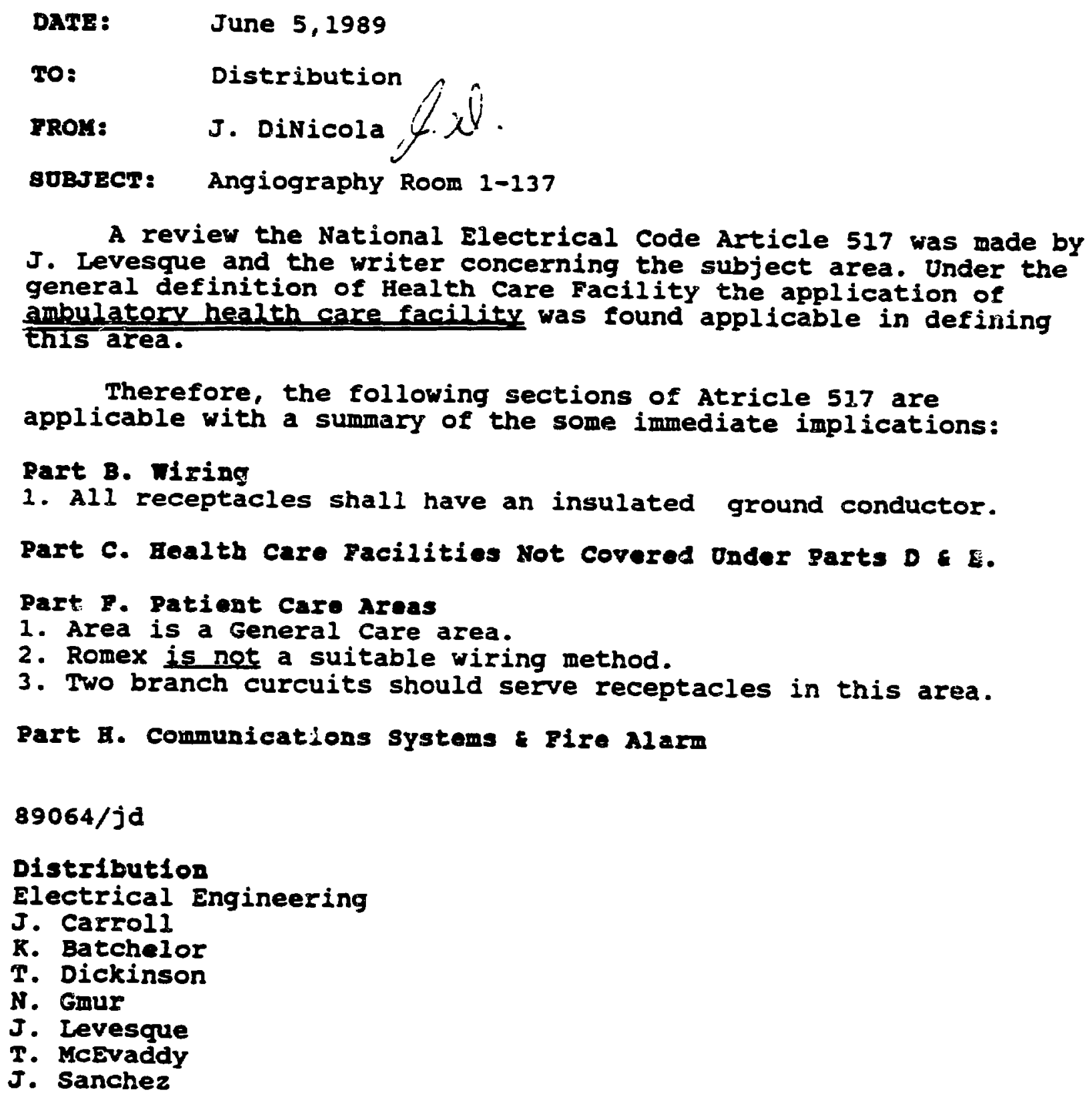

A review the National Electrical Code Article 517 was made by $\mathrm{J}$. Levesque and the writer concerning the subject area. Under the general definition of Health Care Facility the application of ambulatory health care facility was found applicable in defining Eris area.

Therefore, the following sections of Atricle 517 are applicable with a summary of the some immediate implications:

Part B. Niring

1. All receptacles shall have an insulated ground conductor.

Part C. Health Care racilities Not covered Under parts D \& E.

Part F. Patient care nreas

1. Area is a General Care area.

2. Romex is not a suitable wiring method.

3. Two branch curcuits should serve receptacles in this area.

Part H. Communications systems Eire Alarm

$89064 / j d$

Distribution

Electrical Engineering

J. Carroll

K. Batchelor

T. Dickinson

N. Gmur

J. Levesque

T. MCEvaddy

J. Sanchez 
DATE:

TQ:

FROM: C.F. Johnson

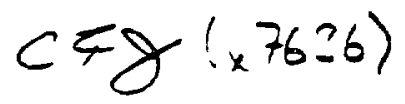

SUBJECT: Freventive Maintenance on 725 Emeroency Generator - FE Equipment \# SESGR-266ta

As per your request in phone conversation and subsequent memo, I have prepared a summary of FM activity performed by Flant Engineering on the generator in question.

Attached please find:

1. Equipment Information - rhis is the nameplate data of this generator as recorded in our FM database.

2. FM Tasb:s by Equipment Fieport - This represents the FM tast:s presently assigned and pertinent information concerning frequency and type.

Z. FM Sperifications - The highlighted specifications apply to this gerierator. These specifications are applied as the tasks mentioned in 1 tem 2 .

At the present time. Flant Engineering does not perform actual load or transfer tests on this generator. We agree that this type of test झhould be performed, but this would require a simulated power fallure in the bullding on a routime basis, at least to the emergency bus. Due to the various user requirements and conflicting operating schedules, a test of this nature is difficult to perform. What this means is that the electrical transfer and distrijution system (emergency) was tested and proven when installed, but $1 \equiv$ not routinely tested as part of the PM schedule. If this or any other portion oi this FM plan needs iurther discussion please feel free tc contact me at e:t. Toj. 
Equipment Number $535 \mathrm{GF}-260 \mathrm{se}$

Name GENEFATOF:

Serial Number 4A-1-2201E

Departinent EF

GroLP HEM

Manufacturer GENEFAL MOTOFS

Model Number $4151-E$

C]ass GE

Original cost $\quad 3756$

Replacement Cost

0

Location ELDG-5JS

BASEMENT

Furchase Date 05/78

Tracl: Spares Y

Meter Fieading $1: 8$

Meter Units HF Usage per Day

0.00

Service Status Im

Charge Number M:5202

\section{Engineering Notes}

ENL \#8E73:,DIESEL, TANK: CAFACITY 6,000,GAL FEF HF 10,75KW, $12 \mathrm{~V}$

Supplies emergency power to 725. 
Spec

No.

Nace

Procedures

Planned

6R-001

EMERGENCY GENERATOR TEST

1. Notjfy Building Rep of test

Craft Hours

Ix/mo

2. Check block heaters

581

2.00

3. Check water level

4. Check belts for wear or cracks

5. Check and clean battery posts and connections

6. Start Engine

7. Verify normal run conditions on gages and thernoneters

B. Test run for 1 hour

Contact supervisor with any operational probleas.

If additional aaintenance 15 required, have repalr work order issued to cover the work

LOG THE FOLLOHING INFORMATION

Engine hours Start tise Stop tise

1. Change beits

2. Change oil and filters

3. Change coolant solution

HE-OO1 MINTERIZE HEAYY EQUIPHENT

1. Check and correct antifreeze concentration in all equipaent HYD. FORM.

HYD. SHOULD OPEN \& CLOSE EASILY.

WUELLER HYOS. FILL RESERVIOR WITH HYD. OIL. 
PH TASKS BY ERUIPMENT

Equipsent No.: 5356R-26668

Group: HEH

Current Meter: 138 HA

Nusber of Tasks: 2
HaEe: SEHERATOR

Lozation: BLDS-5Z5 $i$ BASEMENT

Usage per Day: 0

In Service: IN

Cycle Cycle Crcie Plan. Hext Hext Auto Last Sery. Sery.

Task Type Spec Nane

Dty Unit Type Craft Hours Due

I 5 GR-001 EMERGENCY SENERATOR TEST

2 S GR-002 EMERGENCY GENERATOR SERVICE $-$

$* M=$ Monthly

$A=$ Annually 


\section{BROOKHAVEN NATIONAL LABORATORY}

MEMORANDUM

DATE: $\quad$ May 31,1989

TO: Mr. K. Batchelor, NSLS

FROM: I. Ludw1g, Plant Engineering $(x, 7074)$

SUBJECT: (ILR 254596) Steel Column Modification (Col. \#36)

Pursuant to your request for information $r e$. the above noted subject and for Implementing this information into the FSAR the following applies:

To accommodate the proposed beam Iine equipment a cutout from one flange of existing column \#36 is required. Engineering calculations which address maximum loading conditions indicate that reinforcement of the column is required so that the structural integrity of the column is not impaired. Steel plates welded to the column in a specific configuration will be ut1lized to provide that reinforcement as well as a $4: 1$ Factor of Safety. If you have any questions you can contact me on extension 7874 .

IL $-148: \mathrm{hla}$

cc: T. Timko

J. Levesque

B. Patel 


\section{BROOKHAVEN NATIONAL LABORATOAY}

MEMORANDUM
DATE:
April 6, 1989
TO:
K. Batchalar
FROM:
J. Levesque
9.
QURECT:
X-17 Benmlline Dead Bnd Dietance

The following documents the resalution of the excessive dead end travel distance created by Beamline X-1T3 extencion through the parimeter airlo.

\section{Concerm}

With the construction of Beamline X-17s shielded enclowure, a dead and distance over $90 \mathrm{ft}$ wo created. This was in violation of the Lifo Safety Code ANPA 101-89, Par. 28-2.5.2). The marimum allowable distance is $50 \mathrm{ft}$.

\section{Rerolution}

After reviewing the area with T. Dicloincan, C. Woilandics, R. Zantopp, D. Chapman, and N. Gmur a second exit through the Recovery Rm. was decided on.

By providing a now exit as shown on the attachod diagram, tho dond ond distance will be 50 ft.

The ahaded area between the X-17 transport hutch and X-18 Beamline is not cancidared a narmally cccupied ares. Tho shaded area is cololy for equipment access. The clear width of this region is leas than $9 \mathrm{ft}$. wido.

Summary

The proposed arrangement will improve the lovel of anfoty and comply with DOE Ordars.
J/ec
attachment
c: J. Deits
R: $\quad$ x17beam.
1.2 


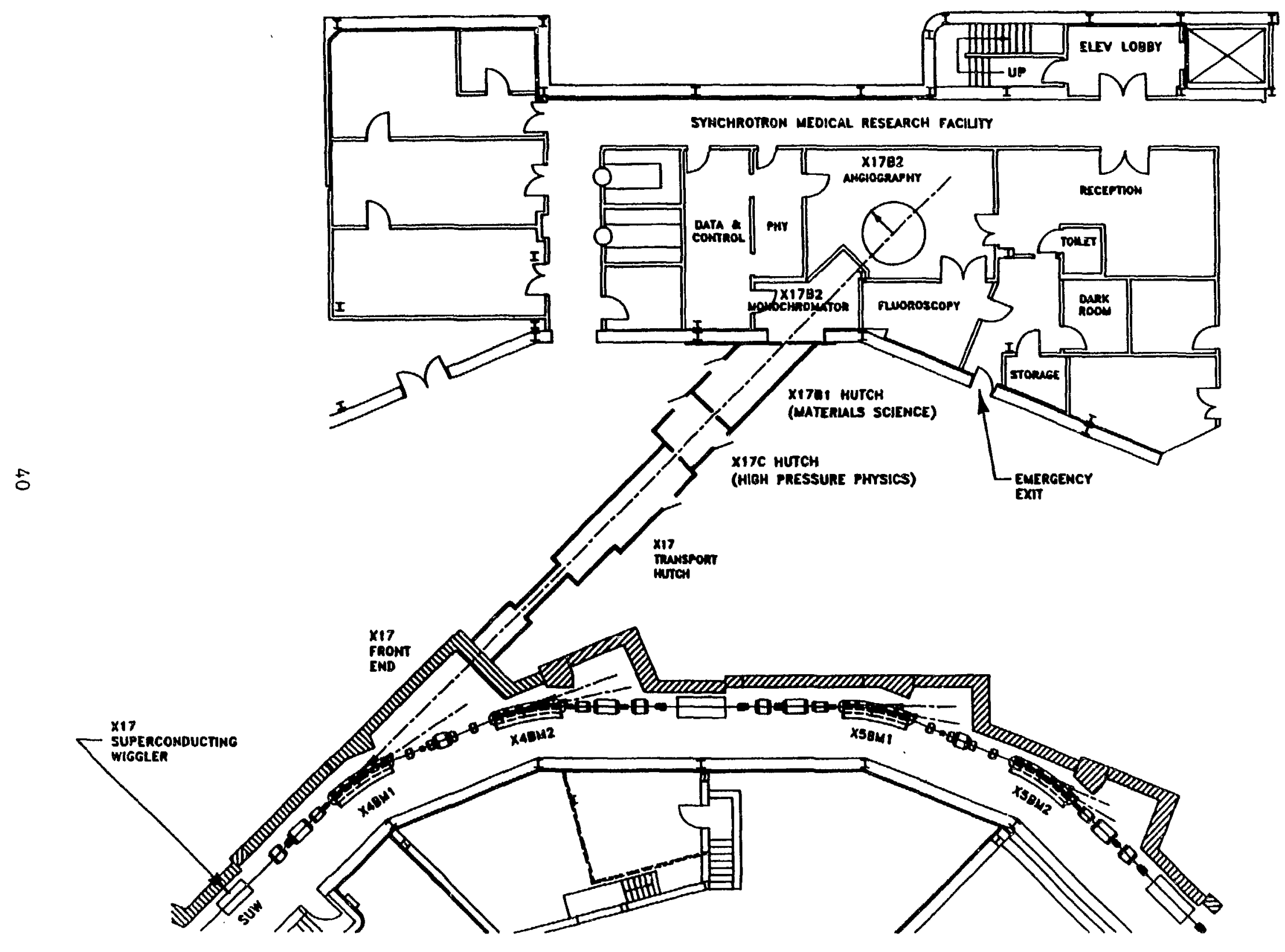




\title{
BROOKHAVEN NATIONAL LABORATORY \\ MEMORANDUM
}

\author{
DATE: $\quad$ March 24, 1989 \\ TO: Medical Department Staff \\ FROM: H. Susskind, Safety Coordinator \\ SUBJECT: Guldelines for Infectlous Daste Disposal
}

Please follow the attached guidelines for disposing of infectious wastes.

HS : dm 
I. DEFINITION

Infectious waste shall mean and-Include the following:

1. Containers with discarded sera that have not been autoclaved.

2. Biological waste which contains discarded excretions, exudates and secretions.

3. Discarded laboratory waste which has come into contact with pathogenic organisms.

4. Blood and body fluids containing visible blood.

5. Animal carcasses exposed to pathogens in research.

6. Sharp items (disposable syringes, needles, scalpels, etc.) that have had contac= with the above items.

\section{COLIECTION}

\section{A. Solid Infectious Waste}

Solid infectious waste (items I. 1-3) is to be collected in plastic lined icecream containers (ICC), avallable from the stockroom. These containers should be sealed by the user with tape and labeled "POTENTIALIY INFECTIOUS". Special tape is available in the Clinical Laboratory. Infectious waste that is also radioactive should be so labeled. Foot operated waste cans should be used Eor all radioactive ICCs.

\section{B. Liquid Infectious Waste}

1. Blood samples are usually present in disposable cencrifuge tubes, vials or syringes. These will be collected in ICCs or puneture resistant, red colored disposable sharps collectors (PRC), as appropriate, for disposal. These containers are available from the stockroom. They should be sealed by the user with tape and labeled "POTENTIALIY INFECTIOUS". Special tape is available in the Clinical Laboratory. Infectious waste that is also radioactive should be so labeled. Foot operated waste cans should be used for all radioactive ICCB.

2. Urine samples $\triangle 5 \circ$ B $B$ collected and the concainers should be sealed by the user wits 6090 and labeled "POTENTIALIY INFECTIOUS". Special tape is avallable i i the Clinical Laboratory. Infectious waste that is also radioactive should be so labeled. Foot operated waste cans should be used for all radioactive ICCs.

\section{Animal Carcasses:}

1. Non-Radieactive

Carcasses are to be properly packaged by the user and placed in the Veterinary Services freezer (Room 9-433-0).

\section{Radioactive}

Carcasses are to be properly packaged and labeied by the user and placed in the designated $s$ \& EP freezer located in the Medical Department basement.

\section{Sharps}

Sharp items are to be collected in PRCs for disposal. Containers holding radioactive waste should be so labeied. 
III. BROCESSING AND DISPOSAL.

\section{A. Solid Infectious Haste}

1. Non-Radieacelve

The sealed containers are to be delivered to Veterinary Services for incineration. The ash will be disposed of in accordante with BNL policy.

2. Radieactive

The containers are to be brought to $S$ \& EP and the appropriate form fillec out (BNL F-2544). S \& EP will have it autoclaved in Veterinary Services. after which it will be sent to Waste Management for disposal.

\section{B. Liquid Infectious Haste}

1. Non-Radivactive

Non-radioactive blood waste is to be autoclaved or Incinerated with solic waste prior to disposal because the residual ilquid volume in centrifuge tubes, syringes, etc. Is too small to be handled separately.

2. Radioactive

Radioactive blood waste containers are to be brought to $S$ \& EP and the appropriate form filled out (BNL F-2544). S \& EP will have it autoclaved In Veterinary Services, after which it will be sent to Waste Management for disposal.

3. Urine

Urine is to be disposed of in the Sanitary system. For special problems or presence of radioactivity, see $S \& E P$.

\section{Animal Carcasses}

1. Non-Radloactive

These carcasses are to be incinerated by Veterinary Services. The ash will be disposed of in accordance with BNL pollcy.

2. Radionctive

Proper disposal will be handled by Waste Management.

D. Sharps

1. Non-Radioactive

The containers are to be brought to the S \& EP office and the appropriate forn filled out (BNL F-2568). S \& EP will have it autoclaved in veterinary Services, after which it will be sent to Waste Management for disposal.

2. Radipactive

The contalners are to be brought to the $S$ EP office and the appropriate form filled out (BNL F-2544). S \& EP will have it autoclaved in veterinary. Services, after which it will be sent to Waste Management for disposal. 
BROOKHAVEN NATIONAL LABORATORY

MEMORANDUM

$\begin{array}{ll}\text { DATE: } & \text { December 15, } 1987 \\ \text { TO: } & \text { Staff, Clinical Research Center; A. D. Chanana, M.D., } \\ \text { FROM: } & \text { Chairman, Medical Department } \\ \text { SUBJECT: } & \text { Prevention of HIV transmission }\end{array}$

The Clinical Research Center is currently following the. August, 1987 , guidelines recommended by the Centers for Disease Control for prevention of HIV transmission, including the protection of health care workers. I have received the recommendations of the Ad Hoc Committee selected by Dr. Chanana to review the CDC guidelines. After consulting further with CDC personnel. I wish to formally institute the recommendations made by the Ad Hoc Committee, with the exception that handwashing is not required between patients undergoing routine phlebotomy unless there 18 a tear in a glove permitting skin contamination with blood or unlees there is visible contamination of the glove with blood. In these situations, the hands should be washed before regloving. Phlebotomy personnel will, however, continue to change gloves between patients.

\section{RREYENTION OF HIY TRANSMISSION}

1. Gloves should be worn when performing venous or arterial punctures. These should be changed after contact with each patient or employee which involves bloodletting. In addition, if there is a tear in a glove permitting skin contamination with blood or if there is visible contamination of the glove with blood, the hands should be washed before reglovine.

2. Needles should not be recapped, bent, or broken. After use, sharps should be placed in puncture-resistant containers.

3. Gloves should be worn when processing blood and body fluids. Masks and protective eyewear should be worn if asrosols are likely.

4. The outside of specimen containers should not be contaminated. If this happens the exposed surface should be decontaminated with gauze soaked in 1:10 Chlorox solution or its equivalent.

5. Mechanical pigetting devices should be used for manipulating all liquids in the laboratory. Mouth pipetting should not be done. 
6. Laboratory rork surfaces should be decontaminated with an appropriate germicide such as $1: 10$ Chlorox solution aster.a blood/body fluid spill and when activities are completed. Refer to blood spill procedure in the CRC infection control guidelines.

7. Hands should be washed after completing lab activities. Lab coats should be removed before leaving the lab area.

8. For appropriate disposal of infectious waste and sharpe, refer to the Waste Disposal Section in the CRC infection control guidelines.

Dis zrtbution:

A. D. Thanana

V. Brooks

D. Fabian

N. Netus 1

J. Matkov1ch

T. Johnson

L. Schlfchteroll

W. Scote

P. Heotis

J. C1zinsky

D. N. Slatkin

Clinical Laboratory

Rad1ology

D. Chr1stman 
Nicholas F. Gmur

Brookhaven National Labosratory

National Synchrotron Light Source

Building $510 E$

Upton, LI, NY 11973

Dear Nick:

Enclosed are comments from Dr. Vacirca concerning the fluoroscope.

Sincerely,

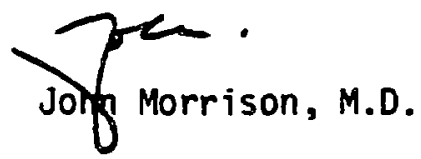

JM: hb

encl. 
Eladk itaven XIat'C Lars

* $R=$ Roentgens

12 aruty8

Scatied Radiation

24 mR fued ..... at . I weten

bred on . Fenso outprent of 2 R/min

$-\cdots$

Sectures radivion $0.1 \%$ of psinasy at lurete. A fit fer weh at 2 minute eneh

OxanRoox

atposition A - Say Laveten (Exos Roow) $24 \mathrm{mr} /$ wech.

with $47.6 \mathrm{~mm}$ peaster shect cock $=2 \mathrm{HVL}$

$24 \mathrm{mr} /$ wed $\times\left(\frac{1}{2}\right)^{2}=6 \mathrm{me} / \mathrm{wreh}$

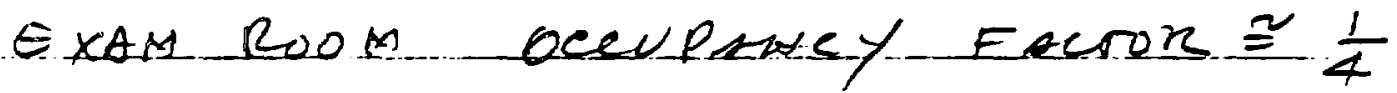

$6 \sin R /$ weeh $x-\frac{1}{4} \cong 1.5 \mathrm{~m} R /$ wech.

Recoptow AnOA

Position B .. abset 2 meters.

Dose rate $24 \mathrm{~m} R /$ wech $x-\left(\frac{1}{2}\right)^{2}=6 \mathrm{~m} R / \mathrm{wh}$

with $2+4 \times 2$ of shat woch $=$

$6 \mathrm{mr} /$ weeh $x\left(\frac{1}{2}\right)^{2}=1.5 \mathrm{mr} /$ wech.

Oce FacIn $\cong 1 / 4$

1.5 mn/weeh $x$ x $\cong 0.4 \mathrm{~m} /$ ween

47

3.J. Vacinctitino 
MOTE:

$12502 y 88$

BASED ON 4 PATIETS PER WEZK

AND $2 \mathrm{~min}$. Of FluOKO EACA.

THE SHIELDXYA - PROULDED BY THE

$4.8 \mathrm{~cm}$ of Gypsun walls is

SUFFICIENT.

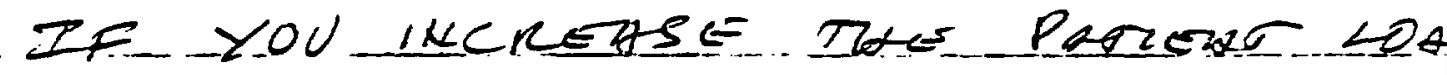

.. BY. 2 on GRERORR, A LmmPA.

THCKnESS TO A HeThHT of $7^{\prime}$ ABOVEA

IS RECOALAENDEO ON EXALINATIOHA

135 AHO RECEDTON AREA (134) INSLUDIN

DOOR AND.ECOSS.

S, G, Veconer, ono

48 


\section{SYNCHROTRON MEDICAL RESEARCH FACUITY}

\section{DOCUMENTATION OF TRANNIG}

The following topics will be covered in training sessions prior to approval by the Principle Investigator, Dr. William Thomlinson, for any person to paricipate in a medical research program on the NSLS Beamline X17B2 involving human studies:

1. BNL and NSLS Safety Orientation

2. Film Badge Orientation

3. X17 Beamline Operations

4. X17 and SMERF Safety Systems

5. Emergency Procedures

6. Human Study Protocols

7. Safety Analysis Report

8. Responsibilities of Personnel

In addition, medical personnel must also have the following:

9. Active Guest Appointment to the Staff of the Clinical Research Center

10. Instruction in their responsibilities during Patient Mode operation of the Angiography Room

Signature of Staff Member:

Date:

Signature of Principle Investigator:

Date:

Rev. 1/3/90 
EXPERIMENTAI LOG FOT PATIENT STUDY

Date Time

Machine

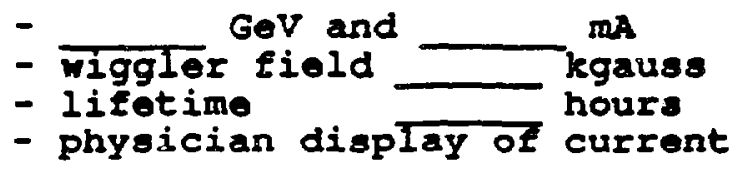

Monochromator

- stepping motor =

- piezo voltage

- tablo position

- water flow ON

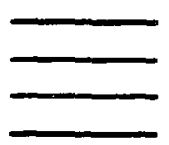

atops

volts

steps

slit - position settings: 1-

2-

3-

4-

Shutters operational

Ionization Chamber

- gas flowing at

$\operatorname{sech}$

- high voltago ON and voltago

- electrometer gaine (x10-=13volta 24-

Chair - chair zero position correct

- phantom scan in correct position

- poaition alignment system OK

Detector

- thermoelectric cooler ON

- Vacuum OK

- high voltago ON and voltage rolta

Power Injector

- Computer interface ox

- Renografin 76 loaded

ECG Machine Operational

Craoh Cart Availablo 


\section{DRAFT}

CALIBRATION SCAN PROTOCOL

Caribration Scans done in Diagnostic Mode

- Scan speed

- I (angi) gain $\mathrm{cm} / \mathrm{scc}$

- NO absorber

- Attenuator 1

- Attenuator $1+2$

- Attenuator $1+2+3$

- Position Scan Absb

- Position + 1

- Position + 1+2

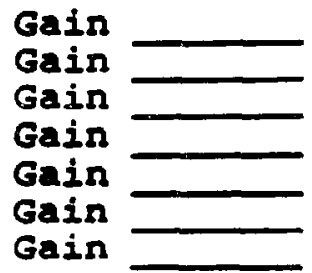

$\operatorname{scan}+1-$ $\operatorname{scan} 1$ scan 1 $\operatorname{scan} 1$. $\operatorname{scan} 1-$ $\operatorname{Scan}+1-$ Scan 1 -
2-

2-

2-

2-

2-

2-

2-

Phantom Scan

- phantor heart poaition

- Interlocks operational

- gain of detector

- manual acalara reaet

- Abrorber IN/OUT

- ecan speed $\mathrm{cm} / \mathrm{sec}$

- scan number

ring scan

- Reithley voltages Vu (Upper) volts V1 (Lower) volta

\section{After scan}

Time

Manual scalera N1=

N2=

N3=

Dose (rad) from Voltagea $=0.218(\mathrm{Vu}+\mathrm{v} 1) \mathrm{F}=$ Rads

Dose $($ rad $)=$ $1.96 \times 10$

$(\mathrm{N} 1+\mathrm{N2})$ Rado

Total Acumulated Dose Rado 


\section{DRAFT}

PATIBNT ROSITIONING SCAN

Description

- Previous exposure dose received

- Safoty astem in PATIENT modo

- ECG heart rate

- Manual scalars reset

- Interlock check

- Safety interlocks all GREEN

- hutch stoppers OREN

- Scanning parameter check

- gain of detector electronics

- acan speed

Rads

- number of framea

- starting frame number

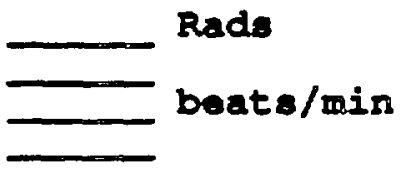

- starting position

- Scan number

- Electron current
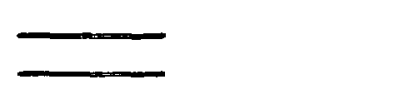

- Absorber IN

- Chair position correct

- Ratient positioned in chair ok

- Iead apron on patient

- Injector Armed (Y/N) If YRS

- Renografin loaded

- tubing connected ( $Y / N$

- Injection parameters

- Door Interlock OK

$\boldsymbol{E}=$

$\mathrm{cm} / \mathrm{sec}$
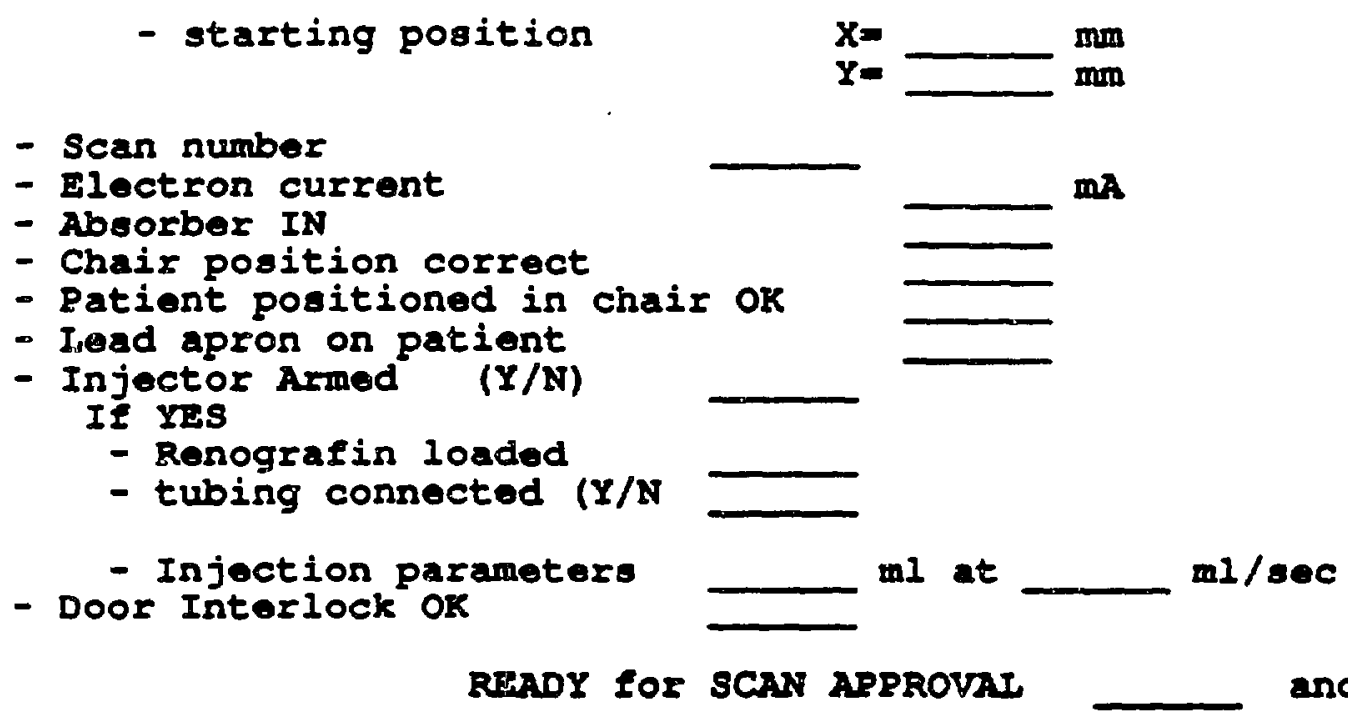

- pationt mored to otarting position

- Computer ready for acan command

- Beam ON

During scan

- Reithley roltages

Vu (Upper)

VI (Lower)

ma

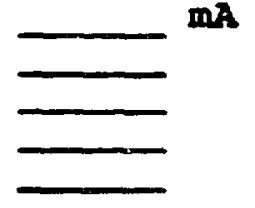

mal at m1/sec

and

\section{After scan \\ Time}

Manual scalers $\mathrm{NI}=$

N2=

N3=

Dose (rad) from Voltages $=0.218(V u+V 1) F=$

volte

volts

$\operatorname{Dose}(\operatorname{rad})=1.96 \times 10$ (N1 + N2) Rado

Total Acumulated Dose Rads 
- Previous exposure dose received

- Safety aystem in PATIENT mode

- ECG heart rate

- Integrated flux display reset

- Manual acalara rosot

- Interlock check

- Safety interlocks all GREEN

- hutch stoppers OPEN

- scanning parametor chock

- gain of detector electronics

- scan speed

- number of Erames

- starting frame number

- starting position
Rada
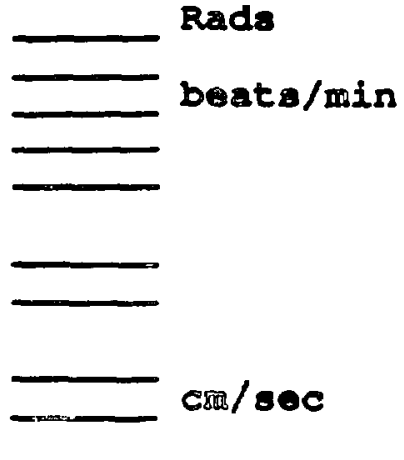

$\cos / \sec$

$\mathbf{P}=$

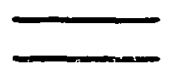

$\mathbf{x}=$

$\mathbf{Y}=$

min

$\min$

- Scan number

- Electron current

$\longrightarrow$

$\underline{-}$

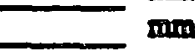

$m$

- Absorber OUT

- Chair poaition correct

- Ratient positioned in chair OK

- Iread apron on patient

- Renografin loaded

- Tubing connected ( $Y / N)$

- Injector parameters

- Injector ARMPD

- Door Interlock ok

READY FOI SCAN APPROVAI

- Patient moved to atarting position ml at

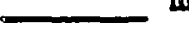

- Computer ready for ucan command

- Beam ON

During scan

- Koithley roltagoa

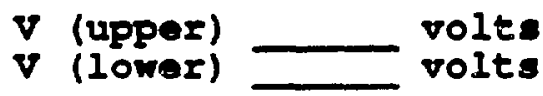

\section{After scan}

Time

Manual scalerg $\mathrm{N} 1=$

N2=

N3=

Dose(rad) from Voltagea $=0.218$ (Vu $+\mathrm{VI}) \mathrm{E}$ Rads

and
$1.96 \times 10$

$(\mathrm{N} 1+\mathrm{N} 2)$ Rads

Total Acumulated Dose Rade 


\section{DRAFT}

Final Calibration scans After Patient Has Left

- In Diagnostic Mode

- Scar Spaed $\mathrm{cm} / \mathrm{gec}$

- Porition + 1+2

- Poaition + 1

- Rosition Att

- Attenuator $1+2+3$

- At tenuator $1+2$

- Attenuator 1

- No absorber
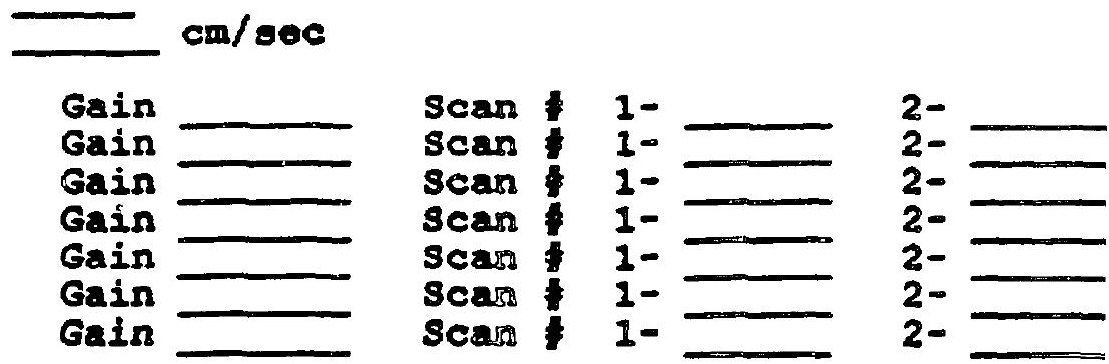

Phantom Scan

- phantom poeition

- gain of detector

- manual scalars reset

- Abrorber IN/OUT

- acan epeed

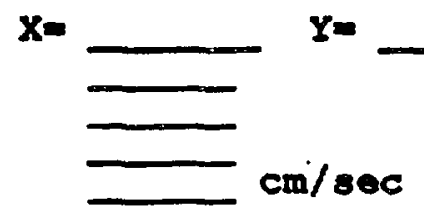

Scan number

During scan

- Keithley voltages
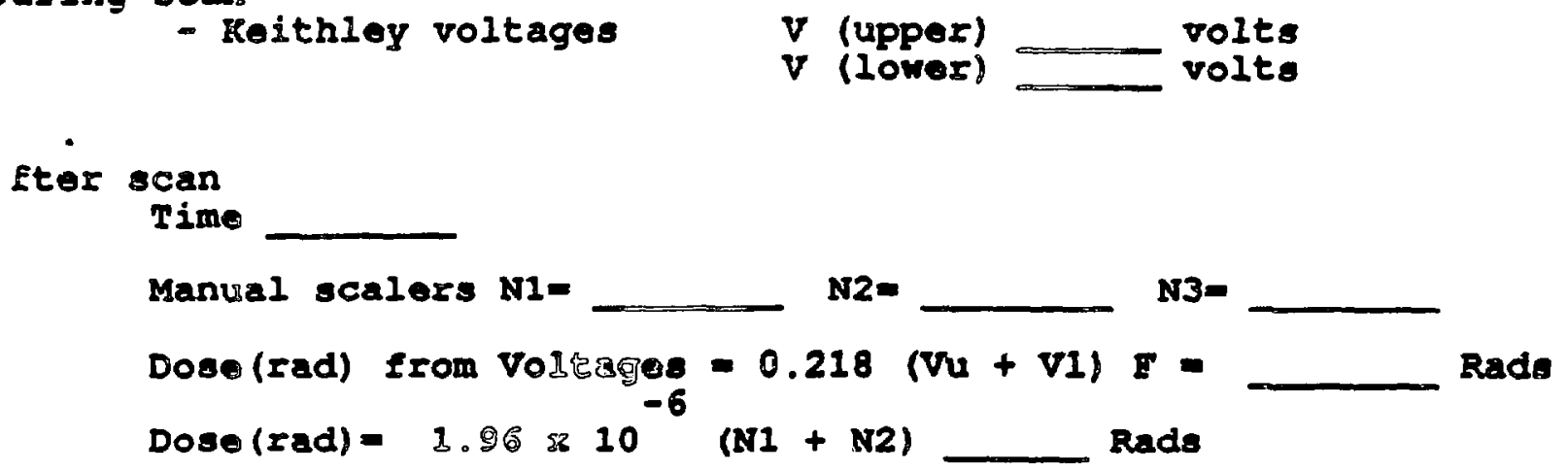


\section{3 \\ Medical Department \\ Brookhaven National Laboratory \\ Upton, New York 11973}

Medical Equipment Maintenance Shop

SOP \#1

\section{STANDING OPERATING PROCEDURE \\ Biomedical Equipment Repair Shop}

1. PURPOSE: This SOP has been prepared to outline current policies, procedures and responsibilities governing the efficient operation of the Biomedical Equipment Repair Shop.

2. SCOPE: This SOP applies to the internal operation and the maintenance of all medical, veterinary, laboratory and $x$-ray equipment supported at this clinical research center and designated satellite activities. It is applicable to all personnel assigned to the Biomedical Equipment Repair Shop.

3. RESPONSIBILITY: The Biomedical Equipment Repair Shop is responsible for installation, repair, preventive maintenance and electrical safety testing necessary to insure proper functioning of all medical equipment within the high.st standards possible. Additional responsibilities are listed in the Appendix.

4. STANDARDS OF BIOMEDICAL MAINTENANCE: Biomedical equipment maintenance must BE OF THE HIGHEST STANDARDS POSSIBLE. Equipment used by medical personnel is most important since its purpose is to save lives and prevent suffering of sick patients. With this purpose as the ultimate objective, the highest standards of maintenance are mandatory.

5. RECOMMENDETIONS AND SUGGESTIONS: Recommendations and suggestions for improving this SOP by individual users are encouraged and should be brought to the attention of the Biomedical Equipment Repair Shop staff.

6. GENERAL: Procedures have been written and attached in APPENDIX format for simplification. Each Appendix provides a reference for detailed information when required. Consult Appendix listing for the appropriate title, paragraph and page number. 
APPENDIX A

PREVENTIVE MAINTENANCE (PM) PROGRAM

1. DEFINITIONS.

a. Preventive Maintenance: The systematic care, servicing, and inspection of equipment for the purpose of maintaining it in a serviceable condition and detecting and correcting incipient faliures before they develop into major defects. PM includes lubrication, minor adjustments, replacement of common hardware or bench stock items, etc.

b. Critical Safety Factors: Deficiencies that if not corrected san result in injury or death to the patient or operator.

c. Deficlency: A malfunction or defect in equipment which causes 1t to be inoperative, inaccurate, or unsafe to operate in its present condiction.

d. Shortcomings: A malfunction or defect in equipment which reduces its effectiveness or capabilities.

\section{TECHNIQUES.}

a. PM will be conducted in accordance with AAMI Vol 8 No 4, manufacturer's 11 terature, and other technical directives, such as the G-29, Veterans Administration services pamphlets. All equipment will be inspected using the shop PM schedule.

b. Nontechnical medical equipment will be given a visual inspection and if at all possible, an operational checkout. Technical medica?. equipment will be given a more complete inspection as described below.

3. PERFORMANCE OF PM. PM will be more than performing an inspection. It is the act of servicing as well as inspecting. Proper PM cannot be accomplished with a clipboard and pen. Personnel assigned to perform $P M$ should be prepared to handle the following tasks: operator.

a. Cleaning. Cleaning in areas not normally accessible to the

b. Lubrication. Unusual lubrication requirements should be accomplished by the MFG or MFG Field Rep.

c. Calibration. Calibration should be regularly performed on items of equipment where accuracy of output is essentia:.

d. Inspection of Critical Safety Factors. Any iten not meeting prescribed safety standards should be reported to on duty orderly, removed fron service and turned in for repalr.

E. Onerational Test. All phases of equipment operation should be checked for normal output or responses.

f. Adjustrents, Parts Replacement. Minor adjustments, replaceant of common hardware (nuts, bolts, and screws, etc) should be done whenever necessary. 
4. PM MANHOUR REQUIREMENTS. Individuals assigned to perform PM will accomplish services to technical items prior to servtcing nontechnical equipment. Items that have an MMCN number maintained are considered technical equipment and will be serviced before nontechnical items. The time allotted to each activity for PM will include some time to perform PM on technical equipment first and if additional time is available, to service nontechnical items. The PM team will not spend more than $1 / 10$ th hour per item, or 10 items per hour, servicing nontechnical items. In addition, the PM tean is expected to accomplish requited PM tasks on technical items within the time published for each item. As individuals become familiar with each item, it is expected that PM tasks will be accomplished at a faster rate.

5. PM RECORDS KEEPING. Repairmen are expected to maintain records properly and turn in required worksheets at the conclusion of each inspection. The PM team will accomplish the following tasks:

a. The Blomedical Equipment Repairman will complete For in Nov. 1976 (Sample attached) and have person. of the sectlor being inspected sign for the second copy. Indicate and items or problems encountered and instruct individuals to initiate a work request. The Biomedical Repalrman will return to the shop, Inform the Shop Foreman of overall outcome of preventive maintenance inspections and turn in the inspection sheets and work request for the respective areas.

b. Ensure Form Nov. 1976 is properly filled out and the activicy supervisor's signature has been secured. One copy of this form will be given to the activity supervisor at the conclusion of the PM visit. One copy will also be turned in to the shop supervisor with all other paperwork.

c. The work order clerk will ensure that all PM actions are inputted into the VAX to ensure PM data is placed on the Automated Haintenance Record. 
1. Works under the general supervision of their Shop Foreman.

2. Answer telephone and personal inquiries regarding the adjustmeat. repalr or overhaul of medical equipment and various other electrical and mechanical appliances and devices.

3. Determines the extent of repairs and/or adjustments required, whether it falls within his capability or should be repalred by outside contractor or depot. Repalrs and checks for proper operation of equipment assigned him for repair.

4. Prepares the necessary administrative paperwork involved with the repair or the paperwork for referral to contractors or depot for repair if beyond their capability.

5. Brings to the attention the the Shop Supervisor or Maintenance Engineer all equipment considered uneconomically repairable.

6. Provides lists of parts required to repair an item when parts are not in stock.

7. Assists in performing preventive maintenance inspections, floor conductivity tests, Ine receptacle and leakage current tests.

8. Monftors the repair or maintenance of equipment on service contracts.

9. Performs other duties as assigned by the Maintenance Supervisor.

10. Records all completed repalrs, callbrations or preventive maintenance services in accordance with established policy. 
APPENDIX C

POLICIES AND PROCEDURES (GENERAL)

1. DUTY HOURS. The normal duty hours are from 0830 hours to 1700 hours Monday through Friday. Lunch break starts at 1200 hours and ends at 1230 hours. Branch personnel will not deviate from this schedule without the permission of the Hospital Administrator.

2. OVERTIME. All overtime will be kept at a minimum level and must be authorized in advance by the branch chief. Personnel will be given compensatory time in accordance with the needs and requirements of the activity.

3. EMERGENCY CALL DUTY. After hours - Shop Supervisor can be called at his home after 1800 .

4. COMPLAINTS. This branch wil maintain an "open door pclicy" and will be avallable at all times to hear complaints and/or problems. Personnel are advised to seek assistance through the chatn of conmand.

5. NEWLY ASSIGNED PERSONNEL. The Shop Supervisor will insure these personnel have completed inprocessing procedures and are orfented toward shop procedures before shop dutles are assigned. This orientation will include a complete review of this procedure.

6. MAINTENANCE OF PRIVATELY OWNED EQUIPMENT. Repair of privately owned equipment will not be accomplished using government owned tools, test equipment, parts, or facilities. The term repair is to include service, calibration, and cleaning.

7. SHOP CLEANL.NESS. AJ.I personnel are responsible for maintaining the shop area, office areas, parts room and storage areas in a high state of cleanliness at all times. 